\title{
Effect of Transport Time of up to 12 Hours on Welfare of Cows and Bulls
}

\author{
Fufa Sorri Bulitta, Samuel Aradom, Girma Gebresenbet \\ Department of Energy and Technology, Swedish University of Agricultural Science, Uppsala, Sweden \\ Email: girma.gebresenbet@slu.se
}

Received 2 December 2014; accepted 29 March 2015; published 31 March 2015

Copyright (C) 2015 by authors and Scientific Research Publishing Inc.

This work is licensed under the Creative Commons Attribution International License (CC BY). http://creativecommons.org/licenses/by/4.0/

(c) (7) Open Access

\begin{abstract}
The aim of the study was to investigate the effects of transport time up to $12 \mathrm{~h}$ on welfare of bulls and cows. Cattle transport vehicle was used for the experiment. Sensors to measure temperature, relative humidity and video camera to monitor behaviour were mounted in observation pen. Eighteen measurements were performed during summer and winter for 4, 8, and $12 \mathrm{~h}$ transport time with three replications. To determine cortisol, glucose, lactate, and creatine kinase concentrations, blood samples were collected before and after transport from 80 bulls, 82 cows and 20 control animals. Cortisol concentration was generally inversely proportional to transport time $(P$ $<0.001$ ). Glucose concentration for cows was the highest at $12 \mathrm{~h}$ and the lowest at $8 \mathrm{~h}$ and for bulls it increased with transport time $(P<\mathbf{0 . 0 0 2})$. Lactate level generally correlated with transport time $(P<0.001)$, but for bulls the highest and the lowest were at 8 and $4 \mathrm{~h}$ in winter. Creatine kinase concentration positively correlated with transport time for bulls and cows but at different rates. Loss of balance and swaying strongly correlated with transport time $(P<0.002)$. Based on behaviour, stress hormones and pH values, an increase from 4 to $8 \mathrm{~h}$ had a higher effect than from 8 to $12 \mathrm{~h}$ transport time on welfare and subsequent meat quality.
\end{abstract}

\section{Keywords}

Animal Welfare, Animal Handling, Behaviour, Swaying, Transport Time

\section{Introduction}

Transport of animals has been increasing steadily in recent decades both on national and international level and it may continue increasing as a result of structural adjustment, specialisation of production systems, internationalisation and globalisation of marketing systems [1]. As a consequence, both transport time and distance 
have increased and this may compromise animal welfare and meat quality. There are also economic losses. In the US National Beef Quality Audit-2000, incidence of carcass bruises was 28.2\% on the chuck (the highest among primal-cut areas) and $14.9 \%$ on the round while the occurrence of "dark-cutting" beef in carcasses was $2.3 \%[2]$.

During handling and transport, animals are subjected to a variety of potential stressors such as heat, cold, poor air quality, vibration and noise. Many of these factors compromise the welfare and health of the animals and also reduce meat quality and may even cause death [3]. Various stress indicators are used to assess the effect of transport on welfare of animals which may include anatomical, physiological and/or behavioural changes [4]. In transport studies, cortisol, glucose, lactate and creatine are relevant parameters to describe the stress levels imposed on animals [5]. It was found that $85 \%$ of animals had creatine kinase values above the reference range (48 - $121 \mu \mathrm{mol} \cdot \mathrm{L}^{-1}$ ) after transport [6].

Behaviour has a number of major advantages in welfare studies. It is not only non-invasive, but also in many cases non-intrusive [7]. The most obvious indicators that an animal is having difficulty coping with handling or transport are changes in behaviour which shows that some aspect of the situation is aversive. The animal may stop moving forward, freeze, back off, run away, vocalize or show other behaviours including lying down [8]-[10]. Behavioural alterations have been related to external stress factors [11] to study welfare using behaviour and scoring system to evaluate the stress on cattle, with special emphasis on loading and unloading. Incidences of abnormal meat $\mathrm{pH}$ value provide information about the welfare of the animals during handling, transport and lairage [12]. Ante-mortem glycogen breakdown is triggered by increased adrenaline in stressful situations or by strenuous muscle activity.

High meat $\mathrm{pH}$ is caused by an abnormally low concentration of lactic acid in the meat, which in turn is a reflection of low muscle glycogen content at slaughter [13]. Beef meat with $\mathrm{pH}_{24}$ greater than 5.5 is thought to be the result of pre-slaughter glycogen depletion, and the consequent inability of muscle to accumulate adequate lactic acid concentration [14]. A study confirmed that, certain physical factors associated with transport could increase stress and limit the decline of meat $\mathrm{pH}$ [15]. These factors include the absence of loading facilities on the farm, transport on a warm day, or a short waiting time at lairage.

It has been documented [16] [17] that although many stressors affect animals in transit, it is the thermal micro-environment within the transport container which poses the greatest threat to the animals' welfare and wellbeing. Other stressors may compromise welfare but the thermal effects can, under extremes, result in mortality in transit. Cattles during transports in Sweden are exposed to temperatures up to nearly $27^{\circ} \mathrm{C}$ in summer and $-16^{\circ} \mathrm{C}$ in winter when loading takes place. The animals can heat up the lorry within $2 \mathrm{~h}$ from $-16^{\circ} \mathrm{C}$ to approximately $0^{\circ} \mathrm{C}$ [18]. Several studies in North America have documented that transportation durations ranging between 2 and $48 \mathrm{~h}$ result in shrink values between 0 and 8\% of body weight (BW) [19]-[21].

Transport time is among the major stress factors during transport. Animals can be transported for $8 \mathrm{~h}$ without special demand on the design of vehicle and feeding conditions [22]. However, transport time more than $8 \mathrm{~h}$ requires certain considerations not to compromise animal welfare. Important report has been made on the effect of transport time length on animal welfare in relation to body weight loss, stress hormones and meat quality [23]. Most of the earlier studies on animal transport in relation to transport time were performed using either stress hormones or animal behaviour separately, and there have been few where animal welfare is evaluated using stress hormone, behaviour and meat quality in the same study. The main objective of the current project was to study the effect of transport time of up to $12 \mathrm{~h}$ on the welfare of cows and bulls, in relation to stress hormones, behavioural alterations, meat $\mathrm{pH}$ values, and temperature and relative humidity when transported from farms to abattoir under conventional conditions

\section{Material and Methodology}

\subsection{Animals and Space Allowance}

In total 162 animals (82 cows and 80 bulls) were used for the field experiment. However, the total number of animals transported in the vehicle was 347. The dimension of the observation box was $2.45 \mathrm{~m} \times 2.50 \mathrm{~m}$ and the mean space allowance was $1.4 \mathrm{~m}^{2} /$ animal. The average weight of the animals was between 450 and $550 \mathrm{~kg}$. EU regulation regarding space requirements for medium size cattle (550 kg) travelling by road or rail is $1.3-1.6 \mathrm{~m}^{2}$ per animal [22]. 


\subsection{Vehicle}

A single deck conventional cattle transport vehicle owned and operated by a commercial transport company was used for the experiment. The vehicle used for transporting the animals was Volvo FM $124 \times 2$, and its loading capacity was $8315 \mathrm{~kg}$. A pen close to the cabin was chosen as a test box. The vehicle was equipped with a natural ventilation system, air suspension system and an adjustable loading ramp. The observation box was fitted with temperature, relative humidity sensors and a video camera for monitoring animals' behaviour.

\subsection{Parameters}

Major stress-inducing factors associated with transport activities were considered to evaluate animal welfare. The parameters and factors such as transport time; temperature; relative humidity; keeping system (tied or loose); loading and unloading conditions; number of stops; space allowance and total number of animals in the vehicle were investigated. In this study, space allowance was constant while transport time varied intentionally. Response parameters such as carcase $\mathrm{pH}$ value at $0,5,18$ and $24 \mathrm{~h}$ post mortem; blood samples for cortisol, glucose, lactate and creatine kinase concentration levels were collected before transport at farms and after unloading at the abattoir. Animal behaviours, temperature and relative humidity were recorded continuously from farms to the abattoir. Other events such as injury, bleeding and death were also documented.

\subsection{1. pH Measurement}

In order to measure meat $\mathrm{pH}$ value, samples were taken from the longissimus dorsi (LD) and chilled for $24 \mathrm{~h}$ at $+4^{\circ} \mathrm{C}$. Temperature and $\mathrm{pH}$ decrease were measured in LD between the $12^{\text {th }}$ and $13^{\text {th }}$ rib immediately after slaughter, as well as at 5,18 and $24 \mathrm{~h}$ post-mortem.

\subsubsection{Blood Parameters}

1) Blood sample collection

A vein puncture technique was used to collect blood samples from coccygeal vein. The samples were used to determine the concentration levels of cortisol, glucose, lactate and creatine kinase. At least $3 \mathrm{~mL}$ of whole blood were obtained using BD vacationer systems (Beliver Industrial Estate, Plymouth, UK) for serum separation and lithium heparin (LH) vacuettes for plasma separation. Collected blood was centrifuged for at least 10 min at $2000 \mathrm{rpm}$ at room temperature using an Eichemeyer centrifuge. Separated cells and plasma were removed using Pasteur pipettes, placed in $1.5 \mathrm{~mL}$ micro tubes and stored at $-20^{\circ} \mathrm{C}$ until analysis.

The time between blood sampling and loading was limited and didn’t allow the animals to rest fully. Some of the experimental animals were also easily agitated during blood sampling and to have representative reference values other control animals were used. For control purpose, blood samples were also collected from 20 cattle (10 bulls and 10 cows that were not transported) from different farms. These control blood samples were used to determine:

a) The concentration levels of cortisol, creatine kinase, glucose and lactate under field conditions. These values were used as references in comparison with those obtained from transported animals.

b) Variations in concentration levels of cortisol, creatine kinase, lactate and glucose at different time of a day. Daily variations in cortisol concentrations levels were studied using Serum samples collected at four different times (similar to times at which samples for the field experiment were taken) a day i.e. 06:00, 09:00, 21:00, and 23:00.

\section{2) Blood analysis}

Different types of devices were used to evaluate the identified blood hormones in the laboratory. Radioimmunoassay Coat-A-Count cortisol kits (Catalog number-TKCO5, Siemens Medical Solution Diagnostics, Los Anglos, CA, USA) was used to measure cortisol values while an automatic Konelabanalyser (Thermo Clinical Labsystems Oy, Vantaa, Finland) was used to analyze Serum glucose and Creatine kinase. A GM7 Analoxanalyser (Analox Instruments LTD, London, UK) was used to measure Lactate concentration levels.

\subsubsection{Animal Behaviour}

In current study behavioural alterations of animals to their new environment were continuously observed and documented during loading, transport and unloading with the help of portable and fixed video cameras. The occurrences of observed behaviours and time taken for each occurrence that the animal showed including number 
of animals in that observation box were continuously recorded during the whole transport processes.

1) Selection of behavioural events and their definition

The most common behavioural events in relation to animal handling and transport observed were identified based on available literature and experiences. These are provided in Table 1 with their respective definitions. These were used to evaluate behavioural alteration of animals during transport activities.

2) Occurrence and frequency of events

During the experiment, occurrence of behaviours, number of animals involved, and duration of events were recorded. Video recordings and documentations of observation made during blood sampling, resting, loading, transport and unloading activities were used to identify the occurrence of events/behaviours. Number of animals involved and total number of animals in the loading compartment were considered when computing frequencies of occurrence of behaviours. Frequency and duration of events were considered for the final behavioural evaluation.

3) Final behavioural quantification

Determining the percentage of animals involved in specific events, or the frequency of events are common methods to study animal behaviour alterations. The formula used (see Equations (1) and (2)) to quantify behaviour evaluates by relating transport time, frequency of behavioural events and number of involved animals. A Similar method has been used [24] in which, the final quantified behaviour was expressed as the product of frequency of events and duration of events.

$$
\begin{gathered}
\text { Frequency }=\frac{A}{B} \\
\text { Behaviour }=\text { Frequency } \times t
\end{gathered}
$$

\begin{tabular}{|c|c|}
\hline Behaviour & Definition \\
\hline Aggressiveness (Ag) & Antagonistic behaviour observed between animals. \\
\hline Eliminations (El) & Defecation and urination. \\
\hline Falls (Fl) & Any part of the body other than the hooves touches the ground involuntarily. \\
\hline Fighting (Ft) & The animal strives to secure more space by attacking other animals. \\
\hline Loss of balance (Ls) & The animal has difficulties holding its natural or walking position and tends to fall down. \\
\hline Moving fast (Mf) & The animal runs rapidly towards the truck or towards the abattoir pens. \\
\hline Refuses to leave original place (Rl) & Unwillingness and resistance of an animal to separate from its group and leave its place. \\
\hline Refuses to mount the ramp (Rm) & Refuses to mount the ramp, but mounts after pushing or/and pulling. \\
\hline Refuse to mount the ramp vigorously (Rg) & Refuses to mount the ramp vigorously, but mounts with difficulties. \\
\hline Refuses to go down the ramp (Rd) & Refuses to go down the ramp, but goes down eventually. \\
\hline Restlessness and change of position (Rc) & The animal is constantly in motion and attempts to find convenient standing orientation. \\
\hline Reversal (Rv) & The animal change direction to move against the animals flow. \\
\hline Slips slightly (Sl) & The animal loses balance temporarily, interfering with its normal walking. \\
\hline Slips strongly (St) & Almost falls down, stretching legs apart. \\
\hline Smelling (Sm) & $\begin{array}{l}\text { The animal bends down to the ground or floor in combination with deep, fast and } \\
\text { interrupted breaths to feel the new environment. }\end{array}$ \\
\hline Swaying (Sw) & The animal swings back and forth or from side to side. \\
\hline Turning (Tn) & The animal rotates or attempts to rotate. \\
\hline Vocalisation (Vc) & Behavioural response expressing discomfort through frequent, high and constant sound. \\
\hline
\end{tabular}

Table 1. Definitions of most observed cattle behaviours’ during loading, transport and unloading. 
where:

A: Occurrences of behaviour (number of all behavioural events);

$B$ : Total number of animals in the observation box;

$t$ : Duration of events in minutes ( the average time of duration of activities of occurrences).

\subsubsection{Temperature and Relative Humidity}

A battery-powered device was used to measure Temperature and relative humidity with electronic logger system which consisted of two parts i.e. portable and battery-operated recording and communication units. It has a PC interface unit which enable to communicate with the recording unit, download parameters, initiate sampling sequences and download the recorded data [25]. In this study, temperature and relative humidity were measured simultaneously and continuously throughout transport time. The results of comprehensive temperature and relative humidity measurements were analysed for the two seasons, two animal categories and three transport times. In addition, number of animals in the pens of the vehicle as a whole, length of loading and unloading time and number of stops were considered for the analysis. The sensitivities of different animal species to ambient temperature and the amount of moisture in the air vary [26]. In this study, temperature-humidity index (THI) was also calculated to determine the level of thermal stress. THI was introduced [27] [28] to evaluate the combined impact of temperature and humidity. It could be expressed as:

$$
\mathrm{THI}=0.8 t_{a b}+\mathrm{RH}\left(t_{a b}-14.4\right)+46.4
$$

where $t_{a b}$ is dry bulb air temperature $\left({ }^{\circ} \mathrm{C}\right)$ and $\mathrm{RH}$ is relative humidity in decimal form. In hot weather conditions, heat stress categories can be described well using THI. THI values are used to set guidelines for safe thresholds of heat stress for safe transportation of animals. Table 2 presents THI threshold values considered for evaluation of environmental conditions in the vehicle.

\subsection{Experimental Design}

This study covered activities of animals from farm up to abattoir and field measurements were made during two seasons. For each season, 18 field measurements were planned that included: two animal categories (bulls and cows); three transport times $(4,8$, and $12 \mathrm{~h}$ ) and three replications. The arrival time at the abattoir was planned to be 09:00. The experimental design included 5 animals (for each trip) $\times 3$ transport times $\times 2$ animal categories $\times 2$ seasons $\times 3$ repetitions. In total, 347 animals were transported from various farms to SCAN AB abattoir in Uppsala (67 km north east of Stockholm). The plan was to transport 90 animals from each category but due to shortage of animals from the same farm, only 82 cows and 80 bulls were blood sampled and transported in the observation box. Age of the bulls was 18 months that were raised for beef production, and the cows were raised for dairy which had different ages. Behavioural study was also conducted on the animals in the observation box. Blood samples (for control) were collected from 20 animals (10 bulls and 10 cows) that were not in transit.

\subsection{Data Analysis}

The collected blood samples were analysed at Swedish University of Agricultural Sciences (SLU) and the results were statistically analysed using a SAS software PC-based program. Analysis of variance (using MANOVA), General linear model and regression analysis were used for data processing.

\section{Results}

\subsection{General}

\subsubsection{Variations in Transport Times}

The selected transport times of 4, 8 and 12 h were supposed to be exact. However time deviations arose due to variations in loading and unloading time variation. The mean and standard deviations for the three classes of transport times were $4 \pm 0.51,8 \pm 0.22$ and $12 \pm 0.15 \mathrm{~h}$.

\subsubsection{Loading and Unloading Method and Time}

Table 3 illustrates animal category, loading and unloading methods and time required in minutes. On the farms, angle of loading ramp varied between $10^{\circ}$ and $15^{\circ}$ and during unloading the angle was $8^{\circ}$ to $10^{\circ}$. Loading and 
Table 2. Recommended THI threshold for farm animals [28].

\begin{tabular}{cc}
\hline THI & Heat stress category \\
$\leq 74$ & Normal \\
$75-78$ & Alert \\
$79-83$ & Danger \\
$\geq 84$ & Emergency \\
\hline
\end{tabular}

Table 3. Mean and standard deviation of loading and unloading time per animal and their ratios.

\begin{tabular}{cccccc}
\hline \multirow{2}{*}{ Activity } & \multicolumn{2}{c}{ Cows } & & \multicolumn{2}{c}{ Bulls } \\
\cline { 2 - 3 } \cline { 5 - 6 } & Loose & Tied & & Loose & Tied \\
\hline Loading time per animal (min) & $2.73 \pm 1.57$ & $3.43 \pm 1.74$ & & $0.77 \pm 0.49$ & $6.5 \pm 3.7$ \\
Unloading time per animal (min) & $1.61 \pm 0.45$ & $1.16 \pm 0.58$ & & $0.58 \pm 2.92$ & $0.86 \pm 0.65$ \\
Ratio of loading/unloading & $1.69 \pm 3.48$ & $2.96 \pm 3$ & & $1.33 \pm 0.17$ & $7.56 \pm 5.69$ \\
\hline
\end{tabular}

unloading times varied significantly $(P<0.002)$ depending on keeping method (loose or tied) and animal categories. It required more time to load and unload tied animals than loose. The highest and lowest loading time per animal was obtained for tied and loose bulls ( $6.5 \pm 3.7$ and $0.77 \pm 0.49$ min) respectively. In the case of cows loading time for tied was ( $3.43 \pm 1.74 \mathrm{~min}$ ) higher than for loose ( $2.73 \pm 1.57 \mathrm{~min})$.

\subsection{3. pH Measurement}

Winter and summer $12 \mathrm{~h}$ cows transport time and $\mathrm{pH}$ values are presented in Figure 1 . The initial $\mathrm{pH}$ values for winter and summer were 6.47 and 6.42 respectively and $\mathrm{pH}_{5}$ value for winter (5.74) was higher than summer (5.61). The ultimate $\mathrm{pH}$ value for winter and summer was 5.5.

A summary of the mean and standard deviations of $\mathrm{pH}$ values are presented in Table 4. The final $\mathrm{pH}_{24}$ values for both winter and summer ranged from 5.58 to 5.28 in cows and 5.60 to 5.34 in bulls. Transport time has no any significant effect on $\mathrm{pH}_{24}$ values in any animal category.

\subsubsection{Blood Parameters}

1) Control samples

Control blood samples were taken at 06:00, 09:00, 21:00 and 23:00 from animals that were not transported. Blood samples for the field experiment were also taken approximately at these times. The values obtained from control animals were used when performing statistical analysis of the samples gathered during the field experiment. In control cows, cortisol concentrations were highest at 6:00 and 9:00 and lowest at 23:00 and in bulls the trend was similar (Figure 2).

2) Transported animals

The concentrations of cortisol, glucose, lactate and creatine kinase in cows and bulls for all transport times performed during the two seasons are summarised in the Figures 3-6. To determine the effect of transport time, the difference between values before and after transport was calculated. However, the absolute values obtained after transport were also checked against the control values obtained during the current project and reference values in the literature.

a) Cortisol

In both bulls and cows during both seasons, the concentration of cortisol was significantly elevated $(P<0.001)$ during short transport and the rate of elevation decreased with an increase of transport time (Figure 3). However in bulls cortisol concentration during $12 \mathrm{~h}$ summer could not decrease with transport time.

b) Glucose

The effect of transport time on concentration of glucose was significant $(P<0.01)$ for both animal category. However, in cows, during both seasons, the highest elevation was observed at 4 and $12 \mathrm{~h}$ and lowest at $8 \mathrm{~h}$ 
Table 4. Summary of $\mathrm{pH}$ values and their standard deviation for different animal categories, seasons and transport times, measurement at $0,5,18$ and $24 \mathrm{~h}$ post mortem.

\begin{tabular}{|c|c|c|c|c|c|c|}
\hline Season & Animal & Transport time, h & $\mathrm{pH}_{0}$ & $\mathrm{pH}_{5}$ & $\mathrm{pH}_{18}$ & $\mathrm{pH}_{24}$ \\
\hline \multirow{6}{*}{ Winter } & \multirow{3}{*}{ Bulls } & 4 & $6.45 \pm 0.12$ & $5.84 \pm 0.22$ & $5.43 \pm 0.18$ & $5.35 \pm 0.09$ \\
\hline & & 8 & $6.61 \pm 0.11$ & $5.90 \pm 0.25$ & $5.78 \pm 0.14$ & $5.56 \pm 0.11$ \\
\hline & & 12 & $6.52 \pm 0.11$ & $5.98 \pm 0.08$ & $5.96 \pm 0.14$ & $5.60 \pm 0.19$ \\
\hline & \multirow{3}{*}{ Cows } & 4 & $6.49 \pm 0.23$ & $5.76 \pm 0.16$ & $5.53 \pm 0.11$ & $5.28 \pm 0.22$ \\
\hline & & 8 & $6.74 \pm 0.33$ & $6.42 \pm 0.19$ & $6.01 \pm 0.24$ & $5.56 \pm 0.18$ \\
\hline & & 12 & $6.12 \pm 0.20$ & $5.56 \pm 0.22$ & $5.36 \pm 0.22$ & $5.35 \pm 0.16$ \\
\hline \multirow{6}{*}{ Summer } & \multirow{3}{*}{ Bulls } & 4 & $6.31 \pm 0.31$ & $5.90 \pm 0.21$ & $5.35 \pm 0.18$ & $5.34 \pm 0.15$ \\
\hline & & 8 & $6.74 \pm 0.33$ & $6.42 \pm 0.19$ & $6.01 \pm 0.24$ & $5.56 \pm 0.18$ \\
\hline & & 12 & $6.12 \pm 0.20$ & $5.56 \pm 0.22$ & $5.36 \pm 0.22$ & $5.35 \pm 0.16$ \\
\hline & \multirow{3}{*}{ Cows } & 4 & $6.18 \pm 0.21$ & $6.46 \pm 0.23$ & $5.59 \pm 0.15$ & $5.58 \pm 0.11$ \\
\hline & & 8 & $6.21 \pm 0.22$ & $5.72 \pm 0.19$ & $5.33 \pm 0.17$ & $5.32 \pm 0.13$ \\
\hline & & 12 & $6.39 \pm 0.18$ & $5.74 \pm 0.17$ & $5.44 \pm 0.16$ & $5.40 \pm 0.14$ \\
\hline
\end{tabular}

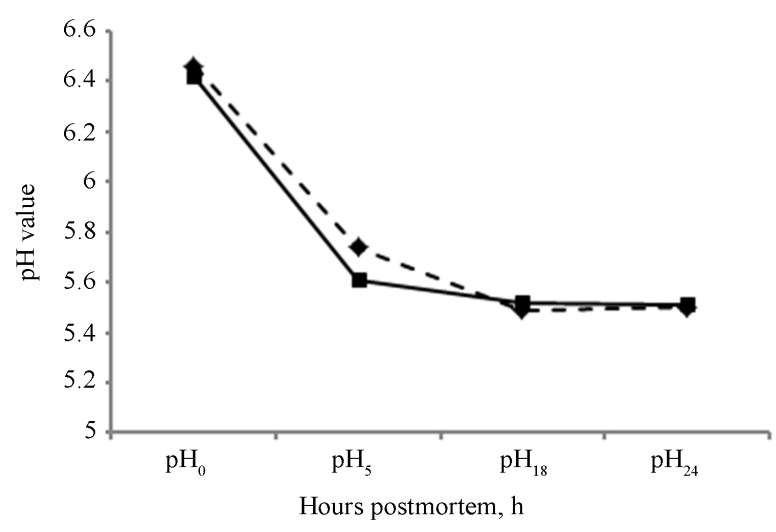

Figure 1. Typical pH values in cow carcases during summer and winter at $12 \mathrm{~h}$ transport time. Winter and summer are represented by dashed and continuous lines respectively.

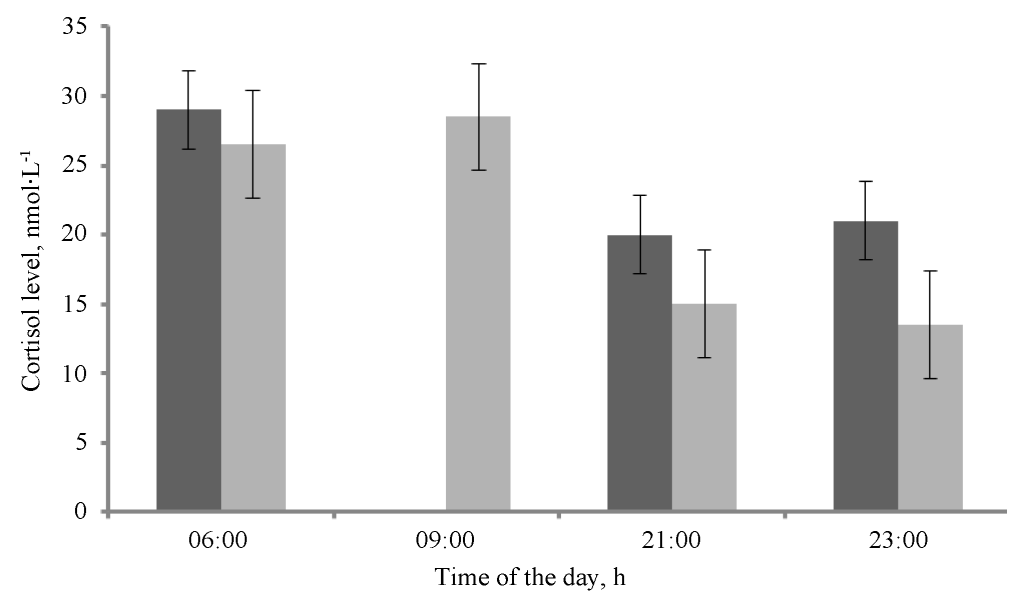

Figure 2. Mean and standard error for variations in cortisol concentrations throughout the day in non-transit bulls and cows (controls). Dark and grey colours represent bulls and cows respectively. 


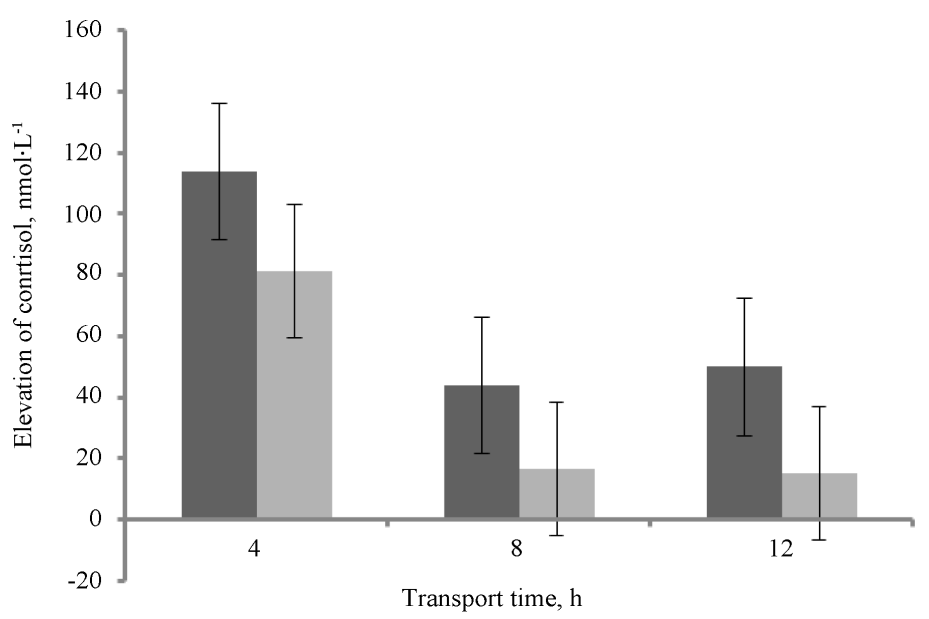

Figure 3. Mean and standard error of cortisol concentration levels in cows for different transport times and seasons. Dark and grey colours represent winter and summer respectively.

transport time (Figure 4(a)). In bulls, glucose concentration increased with an increase in transport time ( $<$ 0.02) and the relationship remained the same for both seasons (Figure 4(b)). Glucose concentration was elevated by $1.52-2.78 \mathrm{mmol} \cdot \mathrm{L}^{-1}$, with the maximum value observed being $7.33 \mathrm{mmol} \cdot \mathrm{L}^{-1}$.

c) Lactate

Concentrations of lactate in the blood increased with an increase in transport time in cows and it was positively correlated with transport time $(P<0.001)$. Concentration level of lactate in winter increased in a linear proportion $(R=0.98)$ as reported in Figure 5(a).

In bulls (summer), the concentration of lactate remained the same for 4 and $8 \mathrm{~h}$ and it increased by about 25\% for $12 \mathrm{~h}$ transport (Figure 5(b)). However, in winter, the concentration level increased with an increase in transport time from 4 to $8 \mathrm{~h}$, and decreased thereafter with an increase in transport time from 8 to $12 \mathrm{~h}$.

d) Creatine kinase

In cows, both during summer and winter, the concentration of creatine kinase increased with an increase in transport time (from 4 to $8 \mathrm{~h}$ ) and remained at a steady state or slight increased thereafter (Figure 6(a)). The highest measured value, for $12 \mathrm{~h}$ transport time, was $109 \mu \mathrm{mol} \cdot \mathrm{L}^{-1}$. In bulls, the rate of increase in concentration of creatine kinase was different during winter and summer. There was slight increase from 4 to $8 \mathrm{~h}$ but from 8 to $12 \mathrm{~h}$ the increase could be as high as 3 fold. During summer measurement concentration level of creatine kinase increased from 4 to $8 \mathrm{~h}$ by about 4 fold and maintained nearly steady state between 8 and $12 \mathrm{~h}$ transport time (Figure 6(b)). The maximum obtained value (for $12 \mathrm{~h}$ ) during winter was $98 \mu \mathrm{mol} \cdot \mathrm{L}^{-1}$. In both animal categories, transport had significant effect on creatine kinase concentration $(P<0.001)$ and was positively correlated with transport time.

\subsubsection{Behaviour Observations and Quantification}

Behaviours like turning, mounting, fighting, change of position and lying were related to loose cattle because movement of tied animals was restricted. The total number of observed animals was 162 and $12 \%$ of the animals (cows and bulls) were tied. Behaviours of animals were quantified as described earlier and the summary of the results is presented in Table 5 and Table 6. Table 5(a) and Table 6(a) present cumulative frequencies and durations of occurrence of behaviours during loading, transport and unloading. Behavioural alterations within 3 intervals of $12 \mathrm{~h}(0$ - 4; 4 - 8 and 8 - 12) transport time are presented in Table 5(b) and Table 6(b).

Elimination (El), smelling (Sm), vocalisation (Vc), aggressiveness (Ag) and refuse to mount the ramp (Rm) were the main behaviours of bulls and cows. But reversal (Rv) was particular behaviour of bulls. When the animals were unloaded the most observed behaviours were elimination (El), smelling (Sm), aggressiveness (Ag), refuse to go down the ramp (Rd) and vocalisation $(\mathrm{Vc})$.

During transport, in both bulls and cows, swaying (Sw), restlessness and change of position (Rc), turning (Tn) and loss of balance (Ls) were among the highest scores noted (Table 5(a) and Table 6(a)) and increased with transport time. In both animal categories, swaying, loss of balance and restlessness and change of position were 


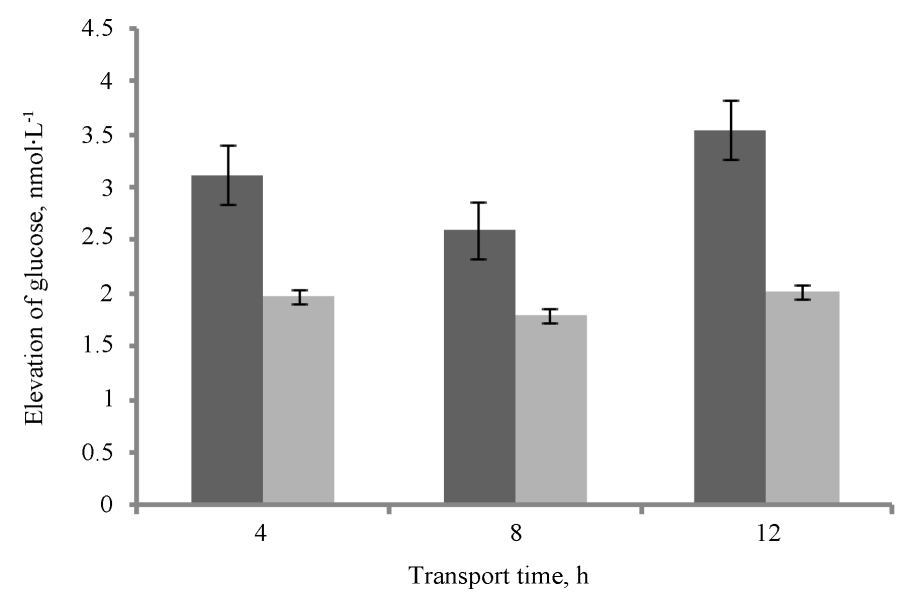

(a)

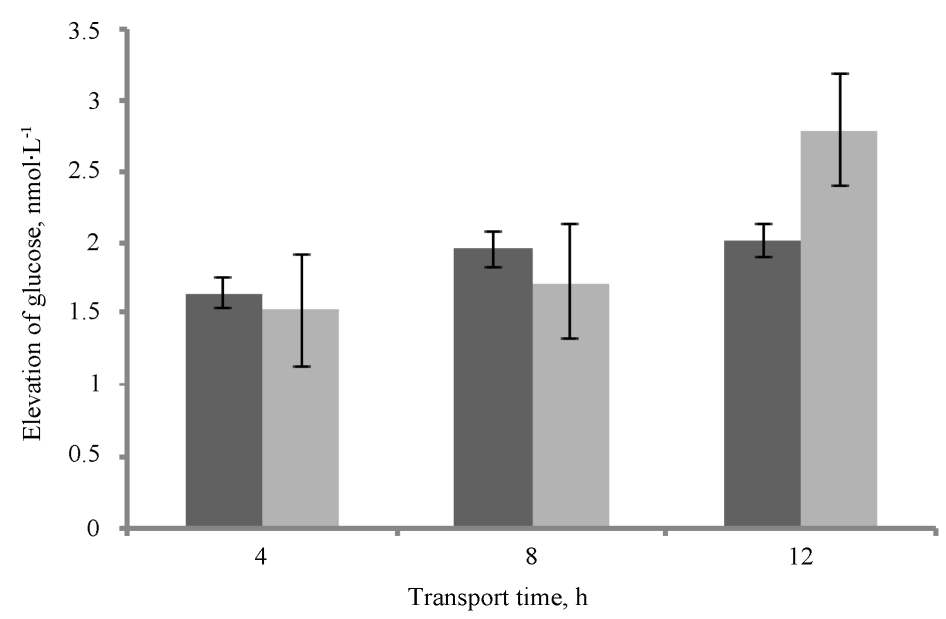

(b)

Figure 4. (a) Mean and standard error of glucose concentration level in cows for the different transport times and seasons. Dark and grey colours represent winter and summer respectively. (b) Mean and standard error of glucose concentration level in bulls for the different transport times and seasons. Dark and grey colours represent winter and summer respectively.

positively correlated with transport time $(P<0.002)$. In cows swaying and loss of balance were almost the same during the three intervals. Turning and restlessness and change of position were lowest at 8 - $12 \mathrm{~h}$ interval and highest at 4 - 8 h interval. In bulls, loss of balance and restlessness and change of position displayed higher values at 4 - $8 \mathrm{~h}$ interval and lower at 8 - 12 h intervals. But swaying increased with the increase of time intervals.

\subsubsection{Temperature and Relative Humidity}

The lowest and highest temperatures were recorded in March $\left(-3^{\circ} \mathrm{C}\right)$ and June $\left(23^{\circ} \mathrm{C}\right)$ respectively. Transport time $(8 \mathrm{~h})$, temperature and relative humidity variations are illustrated in Figure 7. It is an incidence of temperature when it dropped below $0^{\circ} \mathrm{C}$ and varied between $-0.5^{\circ} \mathrm{C}$ and $-1.5^{\circ} \mathrm{C}$. During loading the temperature was $12^{\circ} \mathrm{C}$ and it began to decrease immediately after the vehicle started moving. It can be observed in Figure 7 that temperature was already $-0.5^{\circ} \mathrm{C}$ after about one and half an h. During the whole trip, temperature variation was between $-3^{\circ} \mathrm{C}$ and $12^{\circ} \mathrm{C}$. It took 4:08 h before the temperature began to rise to zero. Initial relative humidity was $31 \%$ at the time of loading and even when the temperature was below $0^{\circ} \mathrm{C}$ relative humidity continued rising from $44 \%$ to $74.3 \%$.

Initial relative humidity and temperature were $38.5 \%$ and $3^{\circ} \mathrm{C}$ respectively (Figure 8). In comparison with other higher initial relative humidity, in this case its growth was gradual not rapid during loading and transport time. 


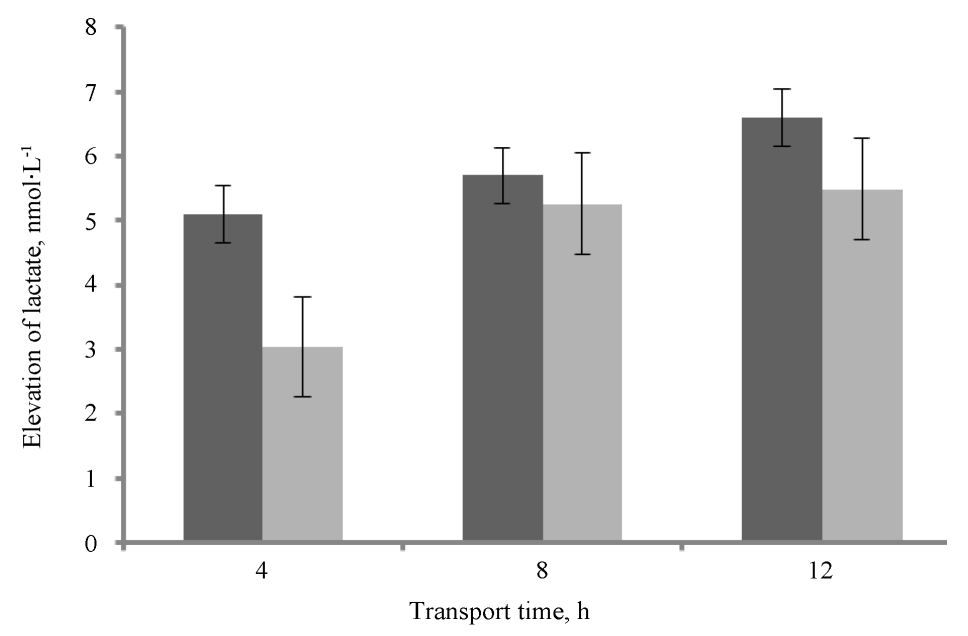

(a)

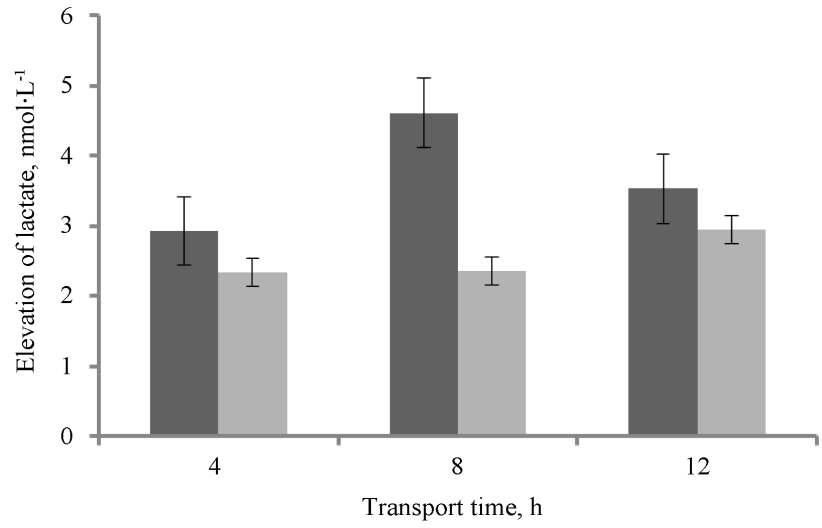

(b)

Figure 5. (a) Mean and standard error of lactate concentration level in cows for different transport times and seasons. Dark and grey colours represent winter and summer respectively. (b) Mean and standard error of lactate concentration level in bulls for different transport times and seasons. Dark and grey colours represent winter and summer respectively.

Figure 9 depicts the changes in temperature and relative humidity during $4 \mathrm{~h}$ transport time. The initial temperature at the time of loading was $-2^{\circ} \mathrm{C}$ and continued falling to $-3^{\circ} \mathrm{C}$ during transport. The total time where temperature remained below zero was $2 \mathrm{~h}$ and 30 minutes. During loading initial relative humidity was $35 \%$. Despite the decline of temperature for the specified duration relative humidity kept on rising to a level of $70.7 \%$. The relative humidity also continued rising when the temperature started rising and reached up to $75 \%$ and thereafter maintained a steady state. During the whole trip temperature varied between $-3^{\circ} \mathrm{C}$ and $3^{\circ} \mathrm{C}$.

Figure 10 illustrates typical temperature and relative humidity curves during summer for $12 \mathrm{~h}$ transport time. In this case, temperature at loading stage was around $22^{\circ} \mathrm{C}$, and decreased gradually and thereafter maintained steady state. However, when extra animals were loaded at about $5 \mathrm{pm}$ the temperature started rising and continued until unloading and reached about $18^{\circ} \mathrm{C}$. During loading relative humidity was $39 \%$ the growth was gradual. During the trip relative humidity varied between $39 \%$ and $86 \%$. In general, the rate of increase in relative humidity and temperature from initial values to maximum values depends on number of animals in the vehicle, initial value of relative humidity prior to loading and length of loading time. The above factors had a significant effect on rate of increase of relative humidity, regardless of length of transport time.

Thermal humidity index (THI)

To study the effect of transport time on THI for both animal categories, all transport time were considered within 4 h intervals ( 0 - 4, 4 - 8 and 8 - 12 h). Maximum, minimum, mean and standard deviations for each interval were computed and are reported in Table 7. 


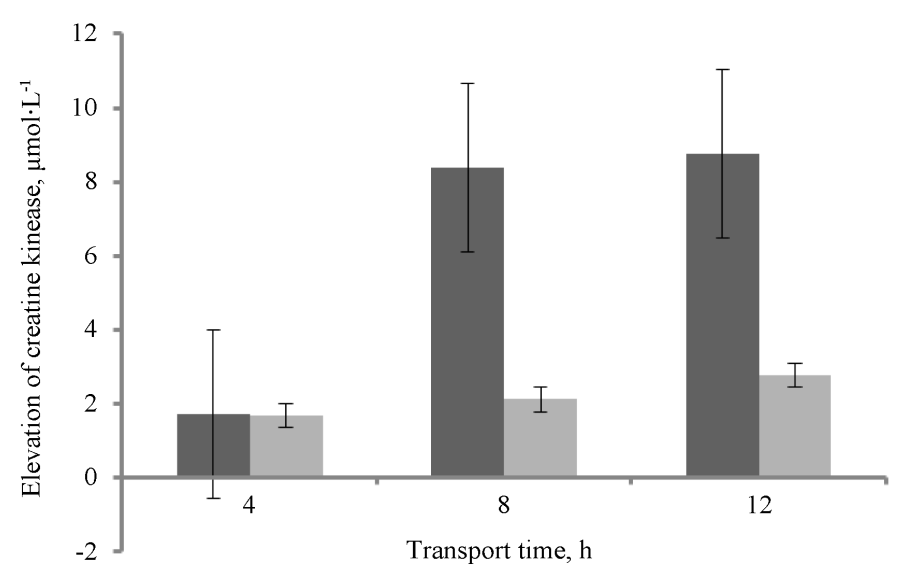

(a)

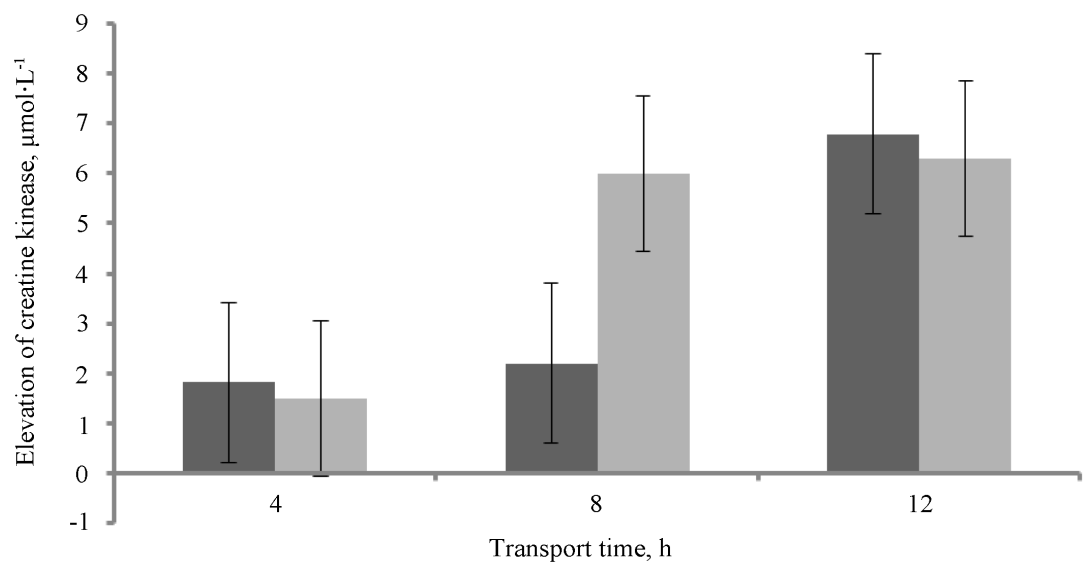

(b)

Figure 6. (a) Mean and standard error of creatine kinase concentration level in cows for different transport times and seasons. Dark and grey colours represent winter and summer respectively. (b) Mean and standard error of creatine kinase concentration level in bulls for different transport times and seasons. Dark and grey colours represent winter and summer respectively.

For winter experiments, the lowest and highest mean values of THI indexes were 39.67 and 46.23 respectively. Summer measurements THI values varied between 51.98 and 67.26 . Although relative humidity of $100 \%$ was noted very often, the THI mean values including the standard deviation of both winter and summer seasons and for the three transport times (4, 8 and $12 \mathrm{~h}$ ) were below the threshold value of 74 and the maximum mean value was 67.26.

\subsubsection{Multivariate Analysis}

The General Linear Model (GLM) was used to assess regression and variance using multivariate analysis of variance (MANOVA). Transport time was independent variable, while blood and behavioural parameters were dependent variables. Considered blood parameters were cortisol (C), lactate (L), glucose (G) and creatine kinase (Ck). Loss of balance (Ls), swaying (Sw), restlessness and change of position (Rc), turning (Tn), fighting (Ft) and elimination (El) were the behaviours considered. Transport, blood hormones and behaviours can be described using a mathematical function that related an input to output variables. In this case transport was an input, blood hormones and behaviours were output variables. Due to transport (input), blood hormones had different values before and after transport similarly behaviours were also different than in the farms. Therefore the main idea of the expression was that the function of transport produced blood hormones and behaviours as output and they were different than before transport and could be expressed as: 
Table 5. (a) Cumulative behaviour of cows during 4, 8 and 12 h transport time. (b) Cows behaviour within 4-h intervals of the $12 \mathrm{~h}$ transport time.

(a)

\begin{tabular}{|c|c|c|c|c|c|c|c|}
\hline \multirow{3}{*}{ Activities } & \multirow{3}{*}{ Behaviour } & \multicolumn{6}{|c|}{ Transport time, $h$} \\
\hline & & \multicolumn{2}{|r|}{4} & \multicolumn{2}{|r|}{8} & \multicolumn{2}{|r|}{12} \\
\hline & & Freq & Freq $\times$ time & Freq & Freq $\times$ time & Freq & Freq $\times$ time \\
\hline \multirow{6}{*}{ Loading } & Ag & 0.50 & 0.16 & 0.25 & 0.08 & 0.67 & 0.25 \\
\hline & El & 0.35 & 0.13 & 0.5 & 0.16 & 0.47 & 0.19 \\
\hline & $\mathrm{Rm}$ & 0.81 & 3.1 & 0.75 & 0.7 & 0.57 & 0.51 \\
\hline & SI & 0.38 & 0.06 & 0.25 & 0.1 & 0.53 & 0.19 \\
\hline & $\mathrm{Sm}$ & 0.64 & 0.26 & 0.5 & 0.46 & 0.3 & 0.24 \\
\hline & Vc & 0.54 & 0.09 & 0.25 & 0.06 & 0.27 & 0.08 \\
\hline \multirow{9}{*}{ Transport } & $\mathrm{Ag}$ & 1.33 & 0.6 & 0 & 0 & 0.44 & 0.02 \\
\hline & $\mathrm{El}$ & 1.67 & 0.17 & 0.33 & 0.11 & 1.11 & 0.11 \\
\hline & $\mathrm{Fl}$ & 0.33 & 0.03 & 0.17 & 0.02 & na & na \\
\hline & $\mathrm{Ft}$ & 1 & 1 & 2.83 & 3.13 & 3 & 3.96 \\
\hline & Ls & 3.33 & 3.28 & 3.5 & 5.55 & 2.78 & 12.94 \\
\hline & Rc & 3.67 & 17.27 & 3.17 & 28.49 & 6.67 & 44.82 \\
\hline & $\mathrm{Sm}$ & 2 & 0.6 & 1.83 & 1.83 & 4.56 & 2.28 \\
\hline & Sw & 7 & 249.09 & 5.83 & 296.51 & 7.56 & 466.75 \\
\hline & $\mathrm{Tn}$ & 4 & 12.5 & 6 & 42.96 & 5 & 38.15 \\
\hline \multirow{6}{*}{ Unloading } & Ag & 0.25 & 0.03 & 0.25 & 0.19 & 0.2 & 0.03 \\
\hline & El & 0.28 & 0.08 & na & na & 0.20 & 0.03 \\
\hline & $\mathrm{Ft}$ & 0.26 & 0.08 & na & na & 0.20 & 0.04 \\
\hline & $\mathrm{Rd}$ & 1 & 0.75 & 1 & 2.25 & na & na \\
\hline & $\mathrm{Sm}$ & 0.46 & 0.15 & 0.75 & 0.21 & 0.47 & 0.22 \\
\hline & Vc & $\mathrm{Na}$ & na & 0.25 & 0.06 & 0.37 & 0.15 \\
\hline
\end{tabular}

$\mathrm{n}(4 \mathrm{~h})=27 ; \mathrm{n}(8 \mathrm{~h})=31$ and $\mathrm{n}(12 \mathrm{~h})=24$, where $\mathrm{n}$ stands for number of animals.

(b)

\begin{tabular}{|c|c|c|c|c|c|c|}
\hline \multirow{3}{*}{ Behaviour } & \multicolumn{6}{|c|}{ Transport time, $h$} \\
\hline & \multicolumn{2}{|c|}{$0-4$} & \multicolumn{2}{|c|}{$4-8$} & \multicolumn{2}{|c|}{$8-12$} \\
\hline & Freq & Freq $\times$ time & Freq & Freq $\times$ time & Freq & Freq $\times$ time \\
\hline Ag & 0.11 & 0.02 & 0.22 & 0.02 & 0.11 & 0.01 \\
\hline $\mathrm{El}$ & 0.22 & 0.04 & 0.44 & 0.03 & 0.44 & 0.04 \\
\hline $\mathrm{Ft}$ & 1.44 & 0.43 & 1.33 & 0.37 & na & na \\
\hline Ls & 0.89 & 4 & 1 & 4.5 & 0.89 & 4.44 \\
\hline Rc & 3.12 & 16 & 2.01 & 19 & 1.54 & 9.82 \\
\hline $\mathrm{Sm}$ & 1.67 & 0.95 & 1.78 & 1.2 & 1.11 & 0.69 \\
\hline Sw & 2.4 & 155 & 3.2 & 163 & 1.96 & 148.75 \\
\hline Tn & 2.5 & 14.6 & 2 & 17.05 & 0.5 & 6.42 \\
\hline
\end{tabular}


Table 6. (a) Cumulative behaviour of bulls during 4, 8 and 12 h transport time. (b) Bull's behaviour within 4-h intervals of the $12 \mathrm{~h}$ transport time.

(a)

\begin{tabular}{|c|c|c|c|c|c|c|c|}
\hline \multirow{3}{*}{ Activities } & \multirow{3}{*}{ Behaviour } & \multicolumn{6}{|c|}{ Transport time, h } \\
\hline & & \multicolumn{2}{|r|}{4} & \multicolumn{2}{|r|}{8} & \multicolumn{2}{|r|}{12} \\
\hline & & Freq & Freq $\times$ time & Freq & Freq $\times$ time & Freq & Freq $\times$ time \\
\hline \multirow{5}{*}{ Loading } & $\mathrm{Ag}$ & 1.2 & 0.2 & 1.6 & 0.9 & 0.67 & 0.31 \\
\hline & $\mathrm{Rm}$ & 0.48 & 3.86 & 0.25 & 0.5 & 0.83 & 0.49 \\
\hline & $\mathrm{Rv}$ & 0.3 & 0.27 & 0 & 0 & 0.33 & 0.06 \\
\hline & Sm & 1.11 & 0.82 & 0.08 & 0.06 & 0.67 & 0.29 \\
\hline & Vc & 0.58 & 0.15 & 0.17 & 0.12 & 1.17 & 0.32 \\
\hline \multirow{8}{*}{ Transport } & El & 0.5 & 0.64 & 0.4 & 0.55 & 0.5 & 0.12 \\
\hline & $\mathrm{Fl}$ & na & na & 0.3 & 0.02 & 0.5 & 0.06 \\
\hline & $\mathrm{Ft}$ & 0.75 & 1.84 & 1.4 & 4.41 & 1.5 & 5.5 \\
\hline & Ls & 1 & 1.92 & 2.3 & 8.72 & 4 & 11.32 \\
\hline & Rc & 1.5 & 23.25 & 3.9 & 21.35 & 4.25 & 82.88 \\
\hline & Sm & 1.25 & 5.5 & 3.6 & 12.74 & 2.75 & 3.19 \\
\hline & Sw & 2 & 42.25 & 7.5 & 179.8 & 11.5 & 695.75 \\
\hline & $\mathrm{Tn}$ & 0.75 & 4.19 & 2.3 & 5.49 & 1.75 & 30.91 \\
\hline \multirow{4}{*}{ Unloading } & $\mathrm{El}$ & 0.33 & 0.12 & 0.08 & 0.1 & na & na \\
\hline & $\mathrm{Ft}$ & 0.29 & 0.08 & 0.08 & 0.19 & na & na \\
\hline & Mf & 0.83 & 0.45 & 0.08 & 0.1 & 1.00 & 0.41 \\
\hline & Sm & 0.41 & 0.29 & 0.08 & 0.05 & 0.5 & 0.17 \\
\hline
\end{tabular}

$\mathrm{n}(4 \mathrm{~h})=30 ; \mathrm{n}(8 \mathrm{~h})=26$ and $\mathrm{n}(12 \mathrm{~h})=24$, where $\mathrm{n}$ stands for number of animals.

(b)

\begin{tabular}{|c|c|c|c|c|c|c|}
\hline \multirow{3}{*}{ Behaviour } & \multicolumn{6}{|c|}{ Transport time, h } \\
\hline & \multicolumn{2}{|c|}{$0-4$} & \multicolumn{2}{|c|}{$4-8$} & \multicolumn{2}{|c|}{$8-12$} \\
\hline & Freq & Freq $\times$ time & Freq & Freq $\times$ time & Freq & Freq $\times$ time \\
\hline $\mathrm{Ag}$ & 0.4 & 0.1 & 0.2 & 0.06 & 0.2 & 0.03 \\
\hline El & 0.2 & 0.4 & 0.12 & 0.6 & 0.18 & 0.2 \\
\hline Ft & 0.5 & 0.2 & 0.3 & 0.06 & 0.1 & 0.01 \\
\hline Ls & 0.65 & 0.8 & 0.8 & 0.5 & 0.05 & 0.2 \\
\hline Rc & 1.8 & 3.8 & 1.45 & 4.3 & 0.75 & 3.22 \\
\hline $\mathrm{Sm}$ & 2.2 & 28.6 & 1.8 & 32.3 & 0.25 & 21.96 \\
\hline Sw & 1.3 & 1.09 & 0.8 & 1.8 & 0.65 & 0.3 \\
\hline $\mathrm{Tn}$ & 4.2 & 183 & 5.3 & 229 & 2 & 283 \\
\hline
\end{tabular}




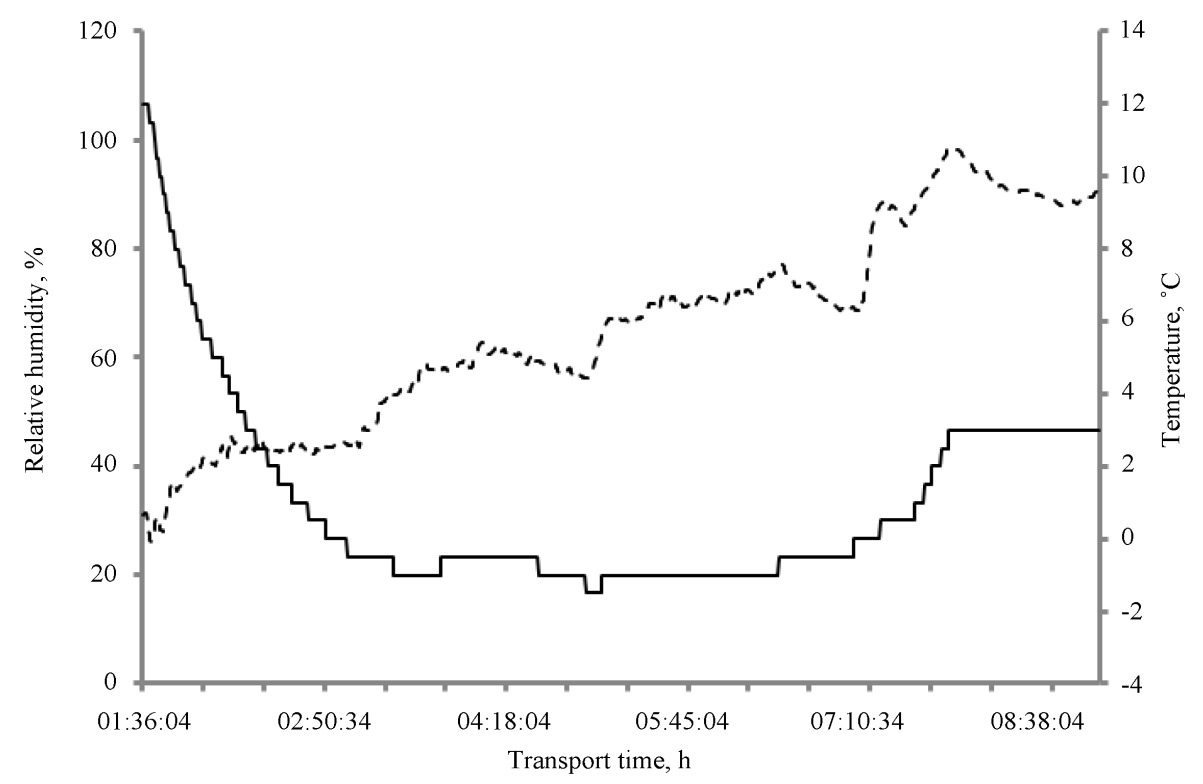

Figure 7. Temperature and relative humidity variations during $8 \mathrm{~h}$ transport time bold and dashed lines stand for temperature and relative humidity respectively.

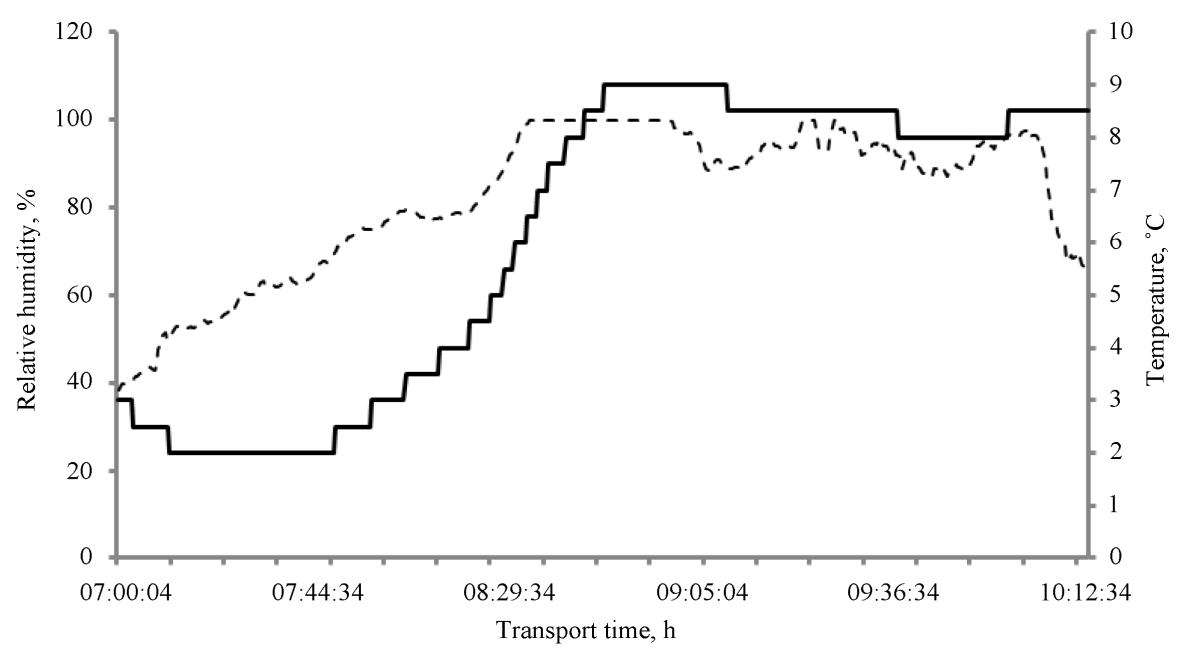

Figure 8. Temperature and relative humidity variations during four4 h transport time. Bold and dashed lines represent temperature and relative humidity respectively.

$$
f(T)=\mathrm{C} \cdot \mathrm{Ck} \cdot \mathrm{L} \cdot \mathrm{G} \cdot \mathrm{LsSwRcTnEl} \cdot \mathrm{Ft}+\varepsilon
$$

The mathematical expression also included standard error, $\varepsilon$ so as to be able to run it in SAS programme. $\varepsilon=n \times p$, and $p$ is a dependent variable. Each of the $p$ can be estimated and tested separately.

Summary of the results are presented in the form of correlation matrices for cows separately (Table 8). The rows and columns in the Tables correspond to 11 variables.

Correlation matrix of variables in cows, as it can be observed in Table 8 that transport time has relatively strong correlation with behaviours like, loss of balance (Ls), swaying (Sw), restlessness and change of position (Rc), fighting (Ft) and turning (Tn). Lactate (L) and creatine kinase (Ck) are the blood parameters that showed fair correlation with transport time whereas glucose (G) was weakly correlated. Elimination and cortisol were negatively correlated with transport time. Certain variables as creatine kinase-lactate (0.6859), fighting-lactate (0.6859) and loss of balance-swaying (0.9235) were inter correlated at different levels and the matrix was significant $(P<0.001)$. Correlation matrix of bulls also demonstrated similar relationship. 


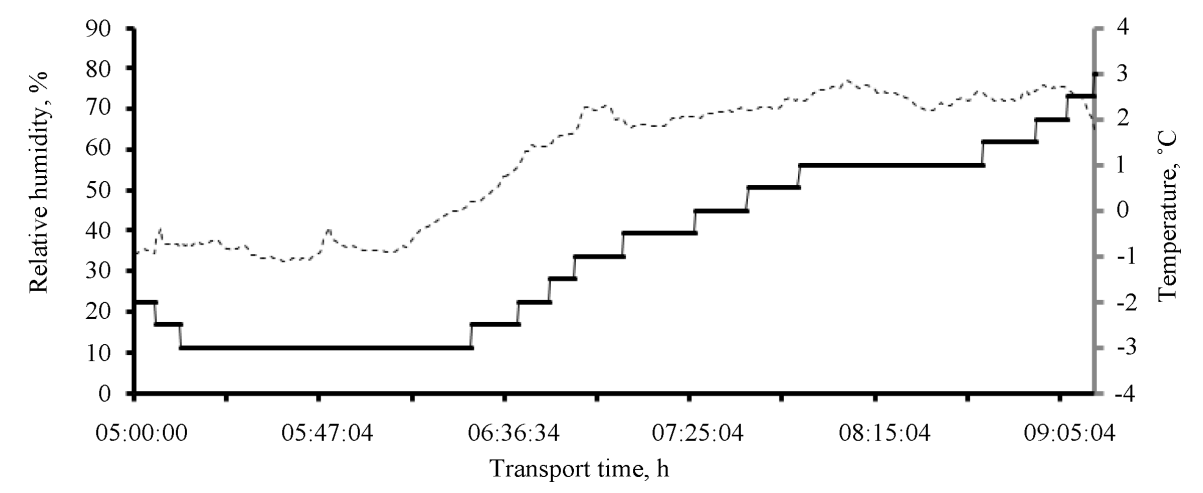

Figure 9. Changes in temperature and relative humidity with transport time Bold and dashed lines represent temperature and relative humidity respectively.

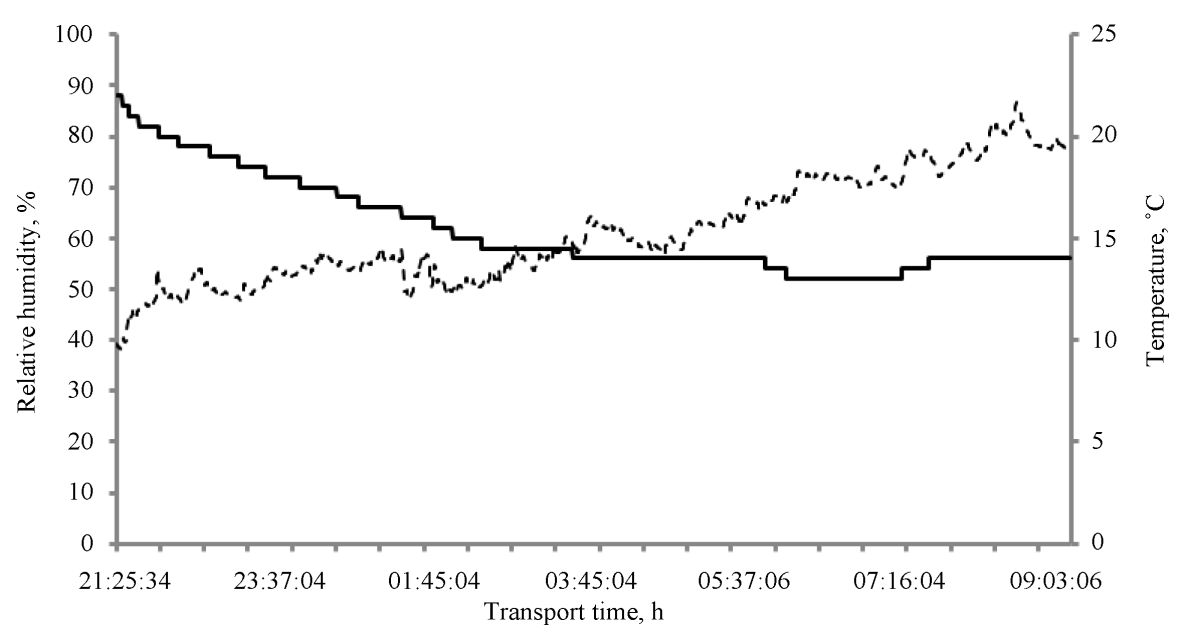

Figure 10. Temperature and relative humidity profile for $12 \mathrm{~h}$ transport time (bulls). Bold and dashed lines represent temperature and relative humidity respectively.

Dendrogram of transport time, blood hormones and behaviours of cows and bulls is reported in Figure 11. In Figure 11(a) transport time (T), behaviours swaying (Sw), restlessness and change of position (Rc), loss of balance (Ls) and fighting (Ft) clustered in pair form at almost same level of similarity, 97\% - 100\%. Lactate (L) and creatine kinase (CK) could also form a pair wise cluster at around 90\% depicting fairly strong correlation with transport time. Behaviour like turning (Tn) and a blood hormone glucose (G) added to the cluster at around 89\% and $62 \%$ respectively. It demonstrated that glucose was weakly correlated with transport time. Cortisol (C) and elimination (El) formed a pair and sequentially added to the main clusters at around 36\% level of similarity.

In Figure 11(b), dendrogram of bulls the clusters are mainly composed of swaying (Sw), restlessness and change of position (Rc) and fighting (Ft) together with transport time. Other variables also formed pair clusters or added to the clusters. In all these cases the level of similarity lies between $90 \%-100 \%$. However cortisol (C) and elimination (El) added to the cluster nearly $37 \%$ same as in the case of cows.

\section{Discussions}

\subsection{Loading and Unloading Methods and Time}

Loading times per animal for loose cows ( $2.73 \mathrm{~min})$ and bulls $(0.77 \mathrm{~min})$ were shorter than for tied cows (2.73 $\mathrm{min}$ ) and bulls $(6.5 \mathrm{~min})$ even unloading times for the respective animals were shorter. Those animals which were raised in tied method could only be loaded and unloaded in the same way. Tied bulls required more time than tied cows to load. Thus loading and unloading was strongly influenced by keeping methods of the animals at the farms, animal's category and transporters' experience. 
Table 7. THI values within 0 - 4, 4 - 8 and 8 - 12 h intervals (with mean and standard deviation) for cows and bulls during winter and summer.

\begin{tabular}{|c|c|c|c|c|c|c|c|c|c|c|}
\hline \multirow{3}{*}{$\begin{array}{l}\text { Animal } \\
\text { category }\end{array}$} & \multirow{3}{*}{$\begin{array}{c}\text { Transport } \\
\text { time \& season }\end{array}$} & \multicolumn{3}{|c|}{ Time } & \multicolumn{3}{|c|}{ Time } & \multicolumn{3}{|c|}{ Time } \\
\hline & & \multicolumn{3}{|c|}{$0-4$} & \multicolumn{3}{|c|}{$4-8$} & \multicolumn{3}{|c|}{$8-12$} \\
\hline & & Max & Min & Mean & Max & Min & Mean & Max & Min & Mean \\
\hline \multirow{8}{*}{ Cows } & Winter & & & & & & & & & \\
\hline & 4 & 47.7 & 40.6 & $42.97 \pm 1.5$ & & & & & & \\
\hline & 8 & 50.3 & 42.7 & $45.37 \pm 1.8$ & 49.2 & 43.5 & $46.5 \pm 1.6$ & & & \\
\hline & 12 & 52. & 44 & $47.17 \pm 2$ & 44.6 & 42.8 & $43.7 \pm 0.4$ & 45.5 & 41.9 & $43.8 \pm 1.2$ \\
\hline & Summer & & & & & & & & & \\
\hline & 4 & 68.7 & 59. & $62.5 \pm 3$ & & & & & & \\
\hline & 8 & 64.5 & 60.5 & $61.8 \pm 1.3$ & 66.2 & 60.5 & $62.8 \pm 1.8$ & & & \\
\hline & 12 & 66.8 & 55.8 & $57.6 \pm 2.7$ & 55.6 & 51.9 & $53.6 \pm 1.5$ & 63.2 & 54.8 & $59.2 \pm 3.3$ \\
\hline \multirow{8}{*}{ Bulls } & Winter & & & & & & & & & \\
\hline & 4 & 50.3 & 41.6 & $45.7 \pm 2.6$ & & & & & & \\
\hline & 8 & 52.7 & 36.9 & $41.9 \pm 4$ & 40.8 & 36.5 & $38.5 \pm 1.4$ & & & \\
\hline & 12 & 45.4 & 40.4 & $42.7 \pm 2.5$ & 42.6 & 39.5 & $40.9 \pm 0.8$ & 46.2 & 39.3 & $42 \pm 2.3$ \\
\hline & Summer & & & & & & & & & \\
\hline & 4 & 62.2 & 57.1 & $59.1 \pm 1.5$ & & & & & & \\
\hline & 8 & 66.5 & 62.8 & $64.2 \pm 0.7$ & 67.1 & 63.9 & $64.9 \pm 1.1$ & & & \\
\hline & 12 & 67.3 & 58.9 & $62.3 \pm 2.5$ & 59.4 & 55.2 & $57.2 \pm 1.1$ & 61.6 & 54.9 & $58.2 \pm 2.1$ \\
\hline
\end{tabular}

Table 8. Correlation matrix of transport time, blood and behavioural parameters in cows.

\begin{tabular}{cccccccccccc}
\hline & $\mathrm{T}$ & $\mathrm{C}$ & $\mathrm{L}$ & $\mathrm{G}$ & $\mathrm{CK}$ & $\mathrm{Ls}$ & $\mathrm{Sw}$ & $\mathrm{Rc}$ & $\mathrm{Tn}$ & $\mathrm{Ft}$ & $\mathrm{El}$ \\
\hline $\mathrm{T}$ & 1.0000 & -0.7599 & 0.7483 & 0.1490 & 0.5356 & 0.9546 & 0.9495 & 0.9943 & 0.7834 & 0.9691 & -0.8660 \\
$\mathrm{C}$ & -0.7599 & 1.0000 & -0.3978 & 0.4595 & -0.2190 & -0.5856 & -0.7639 & -0.7056 & -0.8861 & -0.8522 & 0.8928 \\
$\mathrm{~L}$ & 0.7483 & -0.3978 & 1.0000 & 0.5769 & 0.6859 & 0.6595 & 0.6635 & 0.7245 & 0.7025 & 0.7706 & -0.7402 \\
$\mathrm{G}$ & 0.1490 & 0.4595 & 0.5769 & 1.0000 & 0.6025 & 0.2442 & 0.0505 & 0.1846 & -0.0943 & 0.0599 & 0.0421 \\
$\mathrm{Ck}$ & 0.5356 & -0.2190 & 0.6859 & 0.6025 & 1.0000 & 0.4429 & 0.3138 & 0.5081 & 0.5623 & 0.5757 & -0.5786 \\
$\mathrm{Ls}$ & 0.9546 & -0.5856 & 0.6595 & 0.2442 & 0.4429 & 1.0000 & 0.9235 & 0.9809 & 0.5628 & 0.8516 & -0.6778 \\
$\mathrm{Sw}$ & 0.9495 & -0.7639 & 0.6635 & 0.0505 & 0.3138 & 0.9235 & 1.0000 & 0.9502 & 0.7082 & 0.9059 & -0.7936 \\
$\mathrm{Rc}$ & 0.9943 & -0.7056 & 0.7245 & 0.1846 & 0.5081 & 0.9809 & 0.9502 & 1.0000 & 0.7128 & 0.9373 & -0.8079 \\
$\mathrm{Tn}$ & 0.7834 & -0.8861 & 0.7025 & -0.0943 & 0.5623 & 0.5628 & 0.7082 & 0.7128 & 1.0000 & 0.9126 & -0.9892 \\
$\mathrm{Ft}$ & 0.9691 & -0.8522 & 0.7706 & 0.0599 & 0.5757 & 0.8516 & 0.9059 & 0.9373 & 0.9126 & 1.0000 & -0.9626 \\
$\mathrm{El}$ & -0.8660 & 0.8928 & -0.7402 & 0.0421 & -0.5786 & -0.6778 & -0.7936 & -0.8079 & -0.9892 & -0.9626 & 1.0000 \\
\hline
\end{tabular}

\section{2. $\mathrm{pH}$ Value}

Meat with a $\mathrm{pH}_{24}$ value of 5.8 - 6 or in some cases up to 6.2 is classified as DFD meat [29]. There is no general agreement on the threshold of DFD. In Sweden, the figure of 6.2 is applied, and meat with a $\mathrm{pH}_{24}$ value between 


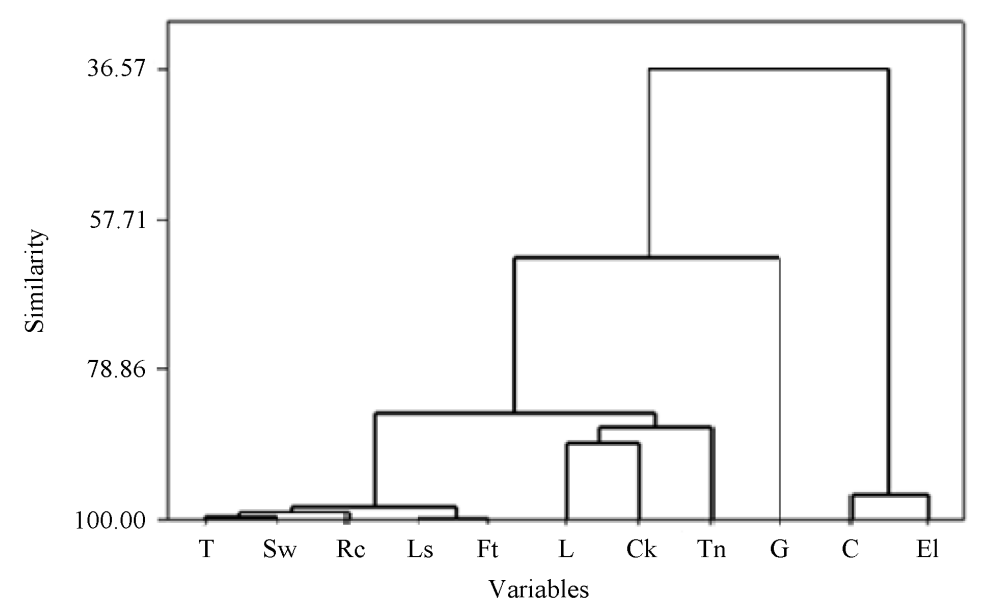

(a)

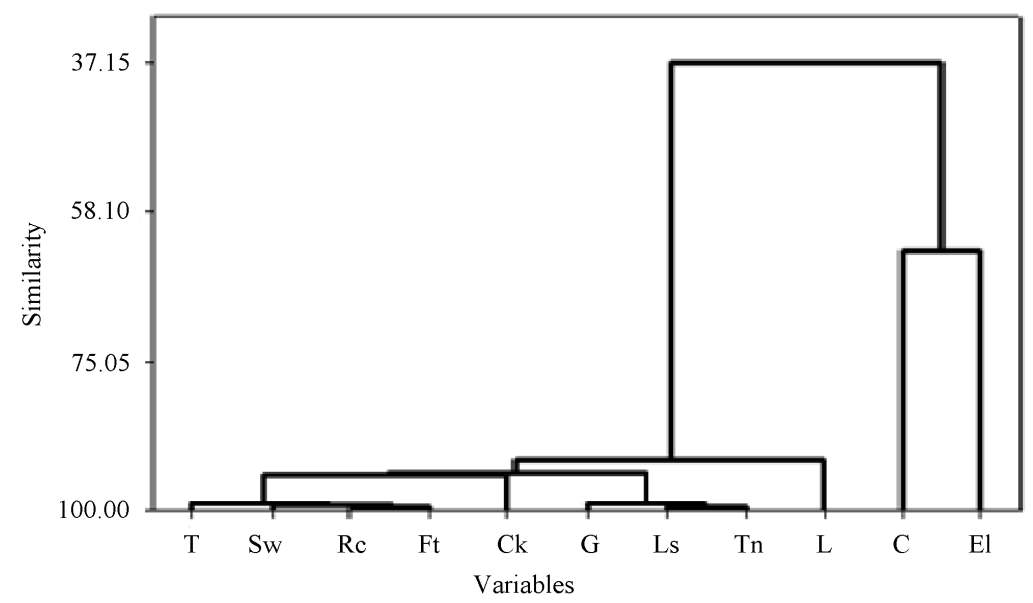

(b)

Figure 11. (a) Dendrogram of transport time and stress related behaviours and blood parameters of cows. (b) Dendrogram of transport time and stress related behaviours and blood parameters of bulls.

5.8 and 6.2 is classified as "meat with low quality". The most common results observed in this study were below the minimum threshold value of 5.4 in cows and bulls. These values can be achieved in beefs if electrical stimulation is applied to the carcass or if the temperature of samples is higher than $4^{\circ} \mathrm{C}$. For the current case, it was probably due to the temperature in the samples. The values between 5.8 and 6 are considered to be of lower meat quality but are not yet classified as DFD meat [30]. In a muscle, such as the longissmusdorsi of ox, from a wellfed and unstressed animal the $\mathrm{pH}$ value will typically fall from about 7.2 to around 5.5 [31].

\subsection{Blood Parameters}

\subsubsection{Cortisol}

In both seasons cortisol level in cows decreased with an increase in transport time. Similar results have been reported by previous researchers. Cortisol concentrations in cattle decreased as a result of habituation during prolonged or repeated exposure to transportation [32]. In a study conducted to investigate the effect of transport time on cattle for 5, 10 and $15 \mathrm{~h}$, it was concluded that cortisol concentration level decreased with transport time [33]. In older cattle, cortisol concentrations increased in response to loading, unloading, and during the first portion of a journey [33]-[35]. Cortisol concentration level in bulls behaved in similar way as in cows but for $12 \mathrm{~h}$ summer transport time, it could not decline with transport time. The bulls which were raised for beef didn't have same level of exposure to human as the dairy cows. Beef cattle not accustomed to handling had significantly 
higher cortisol levels after restraint compared with dairy cattle that were accustomed to handling [36] [37]. Absolute comparisons of cortisol concentration between studies should be made with caution, as cortisol concentrations can vary greatly between individual animals and breeds [34]. Cortisol concentration decreased as transport time increased and at the initial its concentration grew as an immediate response to separation, handling, loading and transport. But after certain transport time the animals habituate to transport related exposures. In the farms cows were more exposed to handling than bulls and the level of cortisol could decline with time (in cows) whereas in bulls it couldn't behave same way as in cows. Animals less exposed to handling may get more stressed during transport situations.

\subsubsection{Glucose}

In cows, concentration level of glucose increased with an increase of transport time. However at 8 h (2.59 $\left.\mathrm{mmol} \cdot \mathrm{L}^{-1}\right)$ and $12 \mathrm{~h}\left(3.59 \mathrm{mmol} \cdot \mathrm{L}^{-1}\right)$ transport time lowest and highest glucose concentrations were noted during winter. Glucose concentrations during summer were also highest at $12 \mathrm{~h}$ and lowest at $8 \mathrm{~h}$ transport time. Glucose concentration level of bulls increased in proportion with the increase in transport time. It was reported that physiological measures including serum glucose and creatine ratio were affected by transport duration in a linear fashion [38]. When an animal is transported, psychological, physiological, and physical stress result in the release of hormones. These releases correspond to elevated blood glucose concentrations [14] [39].

After $12 \mathrm{~h}$ transport time, maximum glucose value for cows was $7.53 \mathrm{mmol} \cdot \mathrm{L}^{-1}$, and the mean reference value in control cows was $5.4 \mathrm{mmol} \cdot \mathrm{L}^{-1}$. In the case of bulls maximum glucose level $\left(9.2 \mathrm{mmol} \cdot \mathrm{L}^{-1}\right)$ was noted during $12 \mathrm{~h}$ transport time and the reference value was $4.7 \mathrm{mmol} \cdot \mathrm{L}^{-1}$. The corresponding reference value in the literature is $4.4 \mathrm{mmol} \cdot \mathrm{L}^{-1}[40]$.

Glucose and lactate concentrations were positively correlated with transport time, but the rate of increase between 8 and $12 \mathrm{~h}$ was lower than that from 4 to $8 \mathrm{~h}$ (or remained steady state). In cows, in summer there was no significant effect, while in winter a higher concentration was observed for $12 \mathrm{~h}$ transport. However, values for $12 \mathrm{~h}$ did not exceed the upper limits [40]. In cows glucose did not increase with transport time, on the other hand there was a linear growth of lactate concentration with transport time and lactate increase in concentration is more correlated with the intensity of muscle activity. Therefore growing in lactate concentration indicated that it took over glucose for the strenuous and prolonged muscle activities.

\subsubsection{Lactate}

Elevation of lactate concentration in cows during winter and summer at $12 \mathrm{~h}$ transport time was 6.6 and 5.49 $\mathrm{mmol} \cdot \mathrm{L}^{-1}$ respectively and it was the highest. The elevation of lactate at $4 \mathrm{~h}$ transport time during winter (5.1 $\left.\mathrm{mmol} \cdot \mathrm{L}^{-1}\right)$ and summer $\left(3.05 \mathrm{mmol} \cdot \mathrm{L}^{-1}\right)$ was lowest.

In bulls, lactate elevation was highest during winter at $8 \mathrm{~h}\left(4.61 \mathrm{mmol} \cdot \mathrm{L}^{-1}\right)$ and in summer at $12 \mathrm{~h}(2.95$ $\mathrm{mmol} \cdot \mathrm{L}^{-1}$ ) transport time. In bulls $15.2 \mathrm{mmol} \cdot \mathrm{L}^{-1}$ was the highest lactate concentration at $12 \mathrm{~h}$ summer transport time whereas the control value was $3 \mathrm{mmol} \cdot \mathrm{L}^{-1}$. Highest lactate concentration level of cows was noted at 4 and $12 \mathrm{~h}$ winter transport time $\left(11.6 \mathrm{mmol} \cdot \mathrm{L}^{-1}\right)$ and it was significantly higher than the control value $1.2 \mathrm{mmol} \cdot \mathrm{L}^{-1}$.

In an assessment of stress in cattle after handling, transport and after slaughter and comparing handling to transport; the authors concluded that transport stress was associated with increased lactate concentrations [41]. Results reported previously by other researchers [33] also showed an increase in lactate concentration with transport time. In cows (winter and summer) and bulls (summer) lactate concentration correlated with transport time. Lactate concentration in bulls (summer) remained the same for 4 and $8 \mathrm{~h}$ and increased at $12 \mathrm{~h}$ but during winter it was lowest and highest at 4 and $8 \mathrm{~h}$ transport time respectively. Lactate concentration was not in consistent with transport time in bulls but concentration in glucose increased with journey time and it was highest at $12 \mathrm{~h}$ transport time. Therefore glucose increase in concentration could manage the muscular activities of the animals.

\subsubsection{Creatine Kinase}

The concentration level of creatine kinase in bulls and cows correlated with transport time during both winter and summer. In both cows and bulls, the increase of creatine kinase concentration due to an increase from 4 to 8 $\mathrm{h}$ transport time was at a higher rate, and maintained almost steady state between 8 and 12 h (Figure 6(a) and Figure 6(b)) or increased slightly. During winter, at $8 \mathrm{~h}$ transport time, highest bulls' creatine kinase concentration (140 $\left.\mu \mathrm{mol} \cdot \mathrm{L}^{-1}\right)$ was measured (after unloading) and it exceeded the control value $\left(87.5 \mu \mathrm{mol} \cdot \mathrm{L}^{-1}\right)$. In cows 
$196 \mu \mathrm{mol} \cdot \mathrm{L}^{-1}$ was the highest level of creatine kinase concentration measured during winter at $8 \mathrm{~h}$ transport time and it was higher than the control value $\left(122 \mu \mathrm{mol} \cdot \mathrm{L}^{-1}\right)$. Creatine kinase concentrations in cattle, during transport have been reported by several researchers. Not only do plasma levels of creatine kinase increase proportionately with the duration of the journey, but they also remain high for several days after transport [33] [35]. During cattle transport there was no muscular damage in the form of bruise. Therefore the release of the enzyme creatine kinase into the blood stream was as a result of vigorous physical exercise and muscular fatigue.

\subsection{Animals Behaviour}

During loading, the most common behaviours of bulls and cows observed were elimination (El), smelling (Sm), vocalization $(\mathrm{Vc})$, aggressiveness (Ag) and refuse to mount the ramp (Rm). Refusing to mount the ramp had the highest score in both animals' categories, reflecting high stress level as consequences of separation and new environment. Cattle if nervous or frightened, defecate more often and usually more liquid feces [42]. Furthermore the author stated that intensive sound occurred when cow was separated from the herd. At the beginning of a journey, cattle are generally anxious and restless and defecate and urinate frequently [35]. Isolation of cattle induces struggling, vocalization, increased heart rate and plasma cortisol levels [43].

In this study, when behaviours of the animals were quantified swaying, (Sw), restlessness and change of position (Rc), turning (Tn), loss of balance (Ls) and fighting (Ft) showed strong correlation with transport time. It was found that, loss of balance is a major determinant in injuries in transported cattle. The author found that one-third of events where cattle were floored during transport were caused by loss of balance during cornering [44]. These behaviours are not common in the farms and the animals showed the behaviours in an attempt to cope with the challenging environment.

Cattle do not readily lie down while being transported and this forced standing causes them to become physically tired during transport in a way that is not seen in pigs and sheep [35]. Due to this behaviour, transport is stressful for cattle and makes them fatigue. The continuous increase in creatine kinase activity with an increase in transport time noted in this study indicates increasing muscular fatigue, which could be attributed to swaying, restlessness and loss of balance behaviours of animals during transport.

\subsection{Temperature and Relative Humidity}

The mean THI values for all transport times and seasons remained below the threshold value of 74, which is within the range of normal values. Maximum values of THI occurred mostly during loading and this might have been due to inadequate ventilation resulting in rapid heat build-up in the loading compartment. This resulted in greater THI mean values when compared with the overall transport time. High initial relative humidity contributed most to rapid increase in humidity, together with rising temperature whereas when the initial relative humidity did not exceed $40 \%$, the growth was gradual and remained mostly around $80 \%$ - 90\% regardless length of transport time. The possible reason for high initial humidity (above 40\%) could be the availability of high moisture after washing the vehicle, and insufficiently ventilated floors and side walls. In those cases where the values were below $40 \%$ prior to loading the rise of relative humidity was not rapid but gradual (Figure 8 ).

In all measurements, whether temperature was rising or falling, relative humidity constantly increased during transport. Temperature dropped below $0^{\circ} \mathrm{C}$ or below the recommended level during certain measurements of the field experiments (Figure 7 and Figure 9). During these trips, temperature remained below zero for at least half of the journeys duration. Sudden drop of temperature from $12^{\circ} \mathrm{C}$ to $-0.5^{\circ} \mathrm{C}$ was also observed within the duration of about 1:30 h (Figure 7). Nevertheless relative humidity was increasing during those incidences to various levels and reached $74 \%$.

Low temperatures and high air humidity may enhance heat dissipation and the animals suffer from cold [45]. The recommended temperature and relative humidity values included upper limits for temperature and relative humidity and lower limits only for temperature [46]. But when temperature is falling and relative humidity is rising, welfare of animals is impaired not only because of temperature but also of the combined effect of temperature and relative humidity.

Therefore low temperature (below $0^{\circ} \mathrm{C}$ ) and high humidity affected welfare of cattle even though only temperature limit is specified in the recommended table (see Table 9). The main causes of temperature below the recommended level were that when outside temperature was below $0^{\circ} \mathrm{C}$ and unnecessarily delayed loading time occurs, and as the poorly insulated container's door remained open during loading. 
Table 9. Recommended minimum and maximum temperature [46].

\begin{tabular}{cccc}
\hline $\begin{array}{c}\text { Age of cattle } \\
\text { in weeks }\end{array}$ & Minimum temperature $\left({ }^{\circ} \mathrm{C}\right)$ & \multicolumn{2}{c}{ Max temperature adjusted for humidity $\left({ }^{\circ} \mathrm{C}\right)$} \\
\cline { 3 - 4 } $0-2$ & 10 & $\mathrm{RH}<80 \%$ & $\mathrm{RH}>80 \%$ \\
$2-26$ & 5 & 30 & 27 \\
$>26$ & 0 & 30 & 27 \\
\hline
\end{tabular}

\section{Conclusions}

The welfare of animals can be affected as a result of transport and poor welfare in animals is caused by the stressful conditions which they encounter during transport processes. This study was conducted to investigate the effect of transport time of up to $12 \mathrm{~h}$ on the welfare of cattle considering climatic conditions, animal behaviour and stress hormones, and final $\mathrm{pH}$ values in carcases. The results indicated that transport and handling activities and transport time had significant effects on animal welfare as evidenced by blood and behaviour parameters. An increase in transport time from 4 to $8 \mathrm{~h}$ had a higher effect than an increase from 8 to $12 \mathrm{~h}$ on the animal welfare. Most of the values of stress hormones and behaviour increased slightly or remained steady state between 8 and $12 \mathrm{~h}$. The measured $\mathrm{pH}_{24}$ values in carcases showed no significant effect of transport time in any animal category.

Cortisol concentration level was the highest for the shortest transport time $(4 \mathrm{~h})$ and the lowest for the $12 \mathrm{~h}$ transport time, but it increased with transport time only in bulls during summer experiments. Concentrations of cortisol, glucose, lactate and creatine kinase in the blood in both cows and bulls after transport were significantly higher than control values. Glucose concentration level in cows during winter and summer was the lowest at $8 \mathrm{~h}$ and the highest at $12 \mathrm{~h}$ transport time. But, in bulls it increased with an increase in transport time. The rate of increase of creatine kinase concentration was higher when transport time increased 4 to $8 \mathrm{~h}$ than from 8 to $12 \mathrm{~h}$ for both cows (winter) and bulls (winter and summer).

Behavioural alterations, particularly loss of balance, swaying, and restlessness were the main effects observed and these were correlated with transport time. There were no reference values to draw plausible conclusions based on these results. However, most of the aforementioned behaviours, with the exception of swaying, increased at a high rate from 4 to $8 \mathrm{~h}$ transport time and remained either steady state or decreased slightly thereafter in most cases. Therefore, an increase in transport time from 8 to $12 \mathrm{~h}$ had a less effect on the behaviour parameters used in this study than increasing from 4 to $8 \mathrm{~h}$. The loss of balance and swaying were highly correlated with the elevation of creatine kinase in cows. It is important to note that determination of acceptable threshold behaviour values requires further comprehensive research.

\section{Acknowledgements}

The authors express their gratitude to: "Branschorganisationen för Kött-och Charkföretagen” for funding the project; to Members of project steering group for important and valuable discussions at all stages of the project progress: Staff members of SCAN AB, particularly Karin Jonsson and Kristher Svensson for continuous support and wonderful collaboration and cooperation, Bert-Olov for his excellent performance and helpful of organizing and facilitating field experiments. Transport companies (Ingstedt Åkeri AB, VAK Djutransport) and farmers for the wonderful cooperation during the field experiments and Musa Adem for his professional input during the field measurements.

\section{References}

[1] Gebresenbet, G. and Eriksson, B. (1998) Effects of Transport and Handling on Animal Welfare, Meat Quality and Environment with Special Emphasis on Tied Cows. Department of Agricultural Engineering, Swedish University of Agricultural Sciences, Uppsala, Report 233.

[2] McKenna, D.R., Roeber, D.L., Bates, P.K., Schmidt, T.B., Hale, D.S., Griffin, D.B., et al. (2002) National Beef Quality Audit-2000: Survey of Targeted Cattle and Carcass Characteristics Related to Quality, Quantity and Value of Fed Steers and Heifers. Journal of Animal Science, 80, 1212-1222. 
[3] Dantzler, R. (1982) Research on Farm Animal Transport in France: A Survey. In: Transport of Animals Intended for Breeding, Production and Slaughter, Martinus Nijhoff, Hague, 218-231.

[4] Siegel, P.B. and Gross, W.B. (2000) General Principles of Stress and Well-Being. CABI Publishing, Wallingford, UK. http://dx.doi.org/10.1079/9780851994093.0027

[5] Gross, W.B. and Siegel, P.B. (1993) General Principle of Stress and Welfare. CAB International, Wallingford, UK.

[6] Kaneko, J.J. (1997) Carbohydrate Metabolism and Its Diseases. Academic Press, California.

[7] Dawkin, M.S. (2004) Using Behaviour to Assess Animal Welfare. Animal Welfare, 13, S3-S7.

[8] Grandin, T. (1980) Observations of Cattle Behavior Applied to the Design of Cattle Handling Facilities. Applied Animal Ethology, 6, 19-31. http://dx.doi.org/10.1016/0304-3762(80)90091-7

[9] Grandin, T. (1982) Pig Behavior Studies Applied to Slaughter Plant Design. Applied Animal Ethology, 9, $141-151$. http://dx.doi.org/10.1016/0304-3762(82)90190-0

[10] Grandin, T. (1989) Behavioral Principles of Livestock Handling. Professional Animal Scientist, 5, 1-11.

[11] Maria, G., Villaroel, M., Chacón, G. and Gebresenbet, G. (2003) Scoring System for Evaluating the Stress to Cattle of Commercial Loading and Unloading. Veterinary Record, 154, 818-821. http://dx.doi.org/10.1136/vr.154.26.818

[12] Grandin, T. (2007) Handling and Welfare of Livestock in Slaughter. CAB International, Wallingford, UK.

[13] Tarrant, P.V. and Grandin, T. (2000) Cattle Transport. CABI Publishing, Wallingford, UK. http://dx.doi.org/10.1079/9780851994093.0151

[14] Kannan, G., Chawan, C.B., Kouakou, B. and Gelaye, S. (2002) Influence of Packaging Method and Storage Time on Shear Value and Mechanical Strength of Intramuscular Connective Tissue of Chevon. Journal of Animal Science, 80, 2383-2389.

[15] Mounier, L., Dubroeucq, H., Andanson, S. and Veissier, I. (2006) Variations in Meat pH of Beef Bulls in Relation to Conditions of Transfer to Slaughter and Previous History of the Animals. Journal of Animal Science, 84, 1567-1576.

[16] Hall, S.J.G. and Bradshaw, R.H. (1998) Welfare Aspects of the Transport by Road of Sheep and Pigs. Journal of Applied Animal Welfare Science, 1, 235-254. http://dx.doi.org/10.1207/s15327604jaws0103_4

[17] Knowles, T.G. (1998) A Review of the Road Transport of Slaughter Sheep. Veterinary Record, 143, 212-219. http://dx.doi.org/10.1136/vr.143.8.212

[18] Wikner, I., Gebresenbet, G. and Nilsson, C. (2003) Assessment of Air Quality in Commercial Cattle Transport Vehicle in Swedish Summer and Winter Conditions. German Veterinary Journal, 110, 100-104.

[19] Jones, S.D.M., Schaefer, A.L., Robertson, W.M. and Vincent, B.C. (1990) The Effects of Withholding Feed and Water on Carcass Shrinkage and Meat Quality in Beef Cattle. Meat Science, 28, 131-139. http://dx.doi.org/10.1016/0309-1740(90)90037-7

[20] Schwartzkopf-Genswein, K.S., Booth, M.E., McAllister, T.A., Mears, G.J., Schaefer, A.L., Cook, N.J., et al. (2006) Effects of Pre-Haul Management and Transport Distance on Beef Cattle Performance and Welfare. Applied Animal Behaviour Science, 108, 12-30. http://dx.doi.org/10.1016/j.applanim.2006.11.012

[21] Zavy, M.T., Juniewicz, P.W., Phillips, W.A. and VonTungeln, D.L. (1992) Effect of Initial Restraint, Weaning, and Transport Stress on Baseline and ACTH-Stimulated Cortisol Responses in Beef Calves. American Journal of Veterinary Research, 53, 551-557.

[22] EU, the European Parliament and of the Council Regulation No. (1/2005) on the Protection of Animals during Transport and Related Operations and Amending Directives 64/432/EEC and 93/119/EC and Regulation (EC) No. 1255/97. Official Journal of the European Union, 2005, L 003.

[23] Ferguson, D.M. and Warner, R.D. (2008) Have We Underestimated the Impact of Pre-Slaughter Stress on Meat Quality in Ruminants? Meat Science, 80, 12-19. http://dx.doi.org/10.1016/j.meatsci.2008.05.004

[24] Aradom, S., Gebresenbet, G., Bulitta, F.S., Bobobee, E.Y. and Adam, A. (2012) Effect of Transport Times on Welfare of Pigs. Journal of Agricultural Science and Technology A, 2, 544-562.

[25] Cargolog FAT 90 V2 Manual. Mobitron AB, Huskvarna, 2009.

[26] Bohmanova, J.J., Misztal, I. and Cole, J.B. (2007) Temperature-Humidity Indices as Indicators of Milk Production Losses Due to Heat Stress. Journal of Dairy Science, 90, 1947-1956. http://dx.doi.org/10.3168/jds.2006-513

[27] Thom, E.C. (1959) The Discomfort Index. Weatherwise, 12, 57-61. http://dx.doi.org/10.1080/00431672.1959.9926960

[28] Mader, T.L., Davis, M.S. and Brown-Brandl, T. (2006) Environmental Factors Influencing Heat Stress in Feedlot Cattle. Journal of Animal Science, 84, 712-719.

[29] Stole Flores, A.P., Linares, C.P., Saaveda, F.F., Serrano, A.B. and Lopez, E.S. (2008) Evaluation of Changes in Management Practices on Frequency of DFD Meat in Cattle. Journal of Animal and Veterinary Advances, 7, 319-321.

[30] Nguyen, N.H., McPhee, C.P. and Trout, G.R. (2006) Response in Carcass Lean pH at 24 Hours Post-Mortem in Lines 
of Large White Pigs Selected for Growth Rate on a Fixed Ration over a Set Time. Livestock Science, 100, 84-90. http://dx.doi.org/10.1016/j.livprodsci.2005.07.005

[31] Warriss, P.D. (2000) Post Mortem Changes in Muscle and Its Conversion into Meat. CAB Publishing, Wallingford, UK.

[32] Lay, D.C., Friend, T.H., Randel, R.D., Jenkins, O.C., Neuendorff, D.A., Kapp, G.M., et al. (1996) Adrenocorticotropic Hormone Dose Response and Some Physiological Effects of Transportation on Pregnant Brahman Cattle. Journal of Animal Science, 74, 1806-1811.

[33] Warriss, P.D., Brown, S.N., Knowles, T.G., Kestin, S.C., Edwards, J.E., Dolan, S.K. and Phillips, A.J. (1995) Effects on Cattle of Transport by Road for Up to Fifteen Hours. Veterinary Record, 136, 319-323. http://dx.doi.org/10.1136/vr.136.13.319

[34] Grandin, T. (1997) Assessment of Stress during Handling and Transport. Journal of Animal Science, 75, $249-257$.

[35] Knowles, G. (1999) A Review of the Road Transport of Cattle. Veterinary Record, 144, 197-201. http://dx.doi.org/10.1136/vr.144.8.197

[36] Lay, D.C., Friend, T.H., Randel, R., Bowers, C.L., Grissom, K.K. and Jenkins, O.C. (1992) Behavioral and Physiological Effects of Freeze and Hot Iron Branding on Crossbred Cattle. Journal of Animal Science, 70, 330-336.

[37] Lay, D.C., Friend, T.H., Bowers, C.L., Grissom, K.K. and Jenkins, O.C. (1992) A Comparative Physiological and Behavioral Study of Freeze and Hot Iron Branding Using Dairy Cows. Journal of Animal Science, 70, 1121-1125.

[38] Cole, N., Camp, T.H., Rowe, L.D., Steven, D.G. and Hutcheson, D.P. (1988) Effect of Transport on Feeder Calves. American Journal of Veterinary Research, 49, 178-183.

[39] Stull, C.L. and Rodiek, A.V. (2000) Physiological Responses of Horses to 24 Hours of Transportation Using a Commercial Van during Summer Conditions. Journal of Animal Science, 78, 1458-1466.

[40] Doornenbal, H., Tong, A.K. and Murray, N.L. (1988) Reference Values of Blood Parameters in Beef Cattle of Different Ages and Stages of Lactation. Canadian Journal of Veterinary Research, 52, 99-105.

[41] Mitchell, G., Hattingh, J. and Ganhao, M. (1998) Stress in Cattle Assessed after Handling, after Transport and after Slaughter. Veterinary Record, 123, 201-205. http://dx.doi.org/10.1136/vr.123.8.201

[42] Ekesbo, I. (2011) Farm Animal Behaviour: Characteristics for Assessment of Health and Welfare. CABI Publishing, Wallingford, UK.

[43] Færevik, G., Jensen, M.B. and Bøe, K.E. (2006) Dairy Calves Social Preferences and the Significance of a Companion Animal during Separation from the Group. Applied Animal Behaviour Science, 99, 205-221. http://dx.doi.org/10.1016/j.applanim.2005.10.012

[44] Tarrant, P.V. (1990) Transportation of Cattle by Road. Applied Animal Behaviour Science, 28, 153-170. http://dx.doi.org/10.1016/0168-1591(90)90051-E

[45] EC, Scientific Committee on Animal Welfare (1999) Standards for Microclimate Inside Animal Transport Road Vehicles. http://ec.europa.eu/food/fs/sc/scah/out35 en.pdf

[46] European Food Safety Authority (EFSA) (2004) Opinion of the Scientific Panel on Animal Health and Welfare on a Request from the Commission Related to the Standards for the Microclimate Inside Animal Road Transport Vehicles. The EFSA Journal, 122, 1-25. 